Article

\title{
Scenario Analysis for Incremental Community Planning in an African Context
}

\author{
Santiago Restrepo Arias *(1), Sara Torabi Moghadam *(1) and Patrizia Lombardi $(\mathbb{D}$ \\ Department of Regional and Urban Studies and Planning, Polytechnic University of Turin, 10125 Turin, Italy; \\ patrizia.lombardi@polito.it \\ * Correspondence: srestrepo.arch@gmail.com (S.R.A.); sara.torabi@polito.it (S.T.M.)
}

Received: 10 August 2020; Accepted: 23 September 2020; Published: 2 October 2020

check for updates

\begin{abstract}
Urban areas are gradually becoming more viable places in terms of life quality than most rural areas. This phenomenon generates human movements, both at a local and at an international scale, the latter usually being labeled as irregular migration. This study aims at analyzing urban scenario proposals that part from incremental urbanism principles to create opportunities for youth and women in the area of Pikine Est (Senegal), a neighborhood with a high vocation toward migration. An integrated planning approach is proposed, where an initial project identification stage reveals through documentary analysis and discussion the adequate project strategies to apply and shines a light on proper life quality indicators (LQIs). In the successive stage, project formulation, future-oriented scenarios are proposed. Finally, at the evaluation stage, each urban scenario is assessed to determine which one contains a more suitable set of strategies in function of the community's needs, employing multi-criteria analysis (MCA) and preference ranking organization method for enrichment evaluation (PROMETHEE) methods. As a result, this study proves through measurable data that assessing incremental urban interventions makes sense in developing communities, not only as a study of their response to scarce financial resources, but also as means to overcome and avoid environmental issues that cities face at a global scale today.
\end{abstract}

Keywords: incremental community planning; multi-criteria analysis (MCA); urban scenarios; life quality indicators (LQIs)

\section{Introduction}

The everlasting transition of human activity towards cities constantly drives more people to want to live as near as possible to the urban center, especially in capital cities [1]. Estimations show that by the year $2050,68 \%$ of the world's population will be living in cities, with an elevated percentage being located in Asia and Africa [2]. Most nations are yet to prepare to face the environmental, economic, social, and cultural impacts of these transitions, and few are equipped with the necessary monetary resources to adapt to such situations that threaten citizens' life quality indicators (LQIs) [3-5]. Once these LQIs are massively affected, it is natural that people keep searching for better opportunities elsewhere, even if it is in different, unknown countries.

According to the International Organization for Migration (IOM) [6], irregular migration is defined as the "movement of persons that takes place outside the laws, regulations, or international agreements governing the entry into or exit from the State of origin, transit, or destination.". Right below this entry in the glossary of terms, the same source specifies how there is no universally accepted definition and clarifies that States are still obliged to protect the rights of irregular migrants. In the efforts of emphasizing this statement, the IOM faces the challenge of collecting data on the actual flows of people that leave one country and arrive at another. One of these results, for instance, includes recordings of 3279 migrants and refugee deaths in 2014 in the Mediterranean Sea, rising to 3777 in 2015, and showing 
a further increase in 2016 with 5085 deaths [7]. These alarming numbers may bring into question the real efficacy of border control strengthening.

Consistent with the statements above, this study is influenced at its base by a project of decentralized cooperation initiated in 2018 between the municipality of Pino Torinese (Italy) and Pikine Est in the city of Pikine (Senegal), formerly conceived of as a peri-urban attachment of the capital Dakar before the Act of Decentralization of 2013 [8]. The main objectives and actions of the project are to support the creation of opportunities that would serve as viable alternatives to migration for youth and women in the community. Such actions included, for instance, formation courses in informatics, equipping local libraries with documentation on job research, alphabetization courses, and building a sportive field.

The Pino Torinese-Pikine Est project highlights the main weak spots of the community to be addressed: cultural opportunities, sports sponsoring, household waste management, and reflection regarding irregular migration. These weak spots, obtained through stakeholder discussion, include general and specific issues affecting the community at different levels. Results derived from the fusion of these stakeholder declarations plus the literature review, study area analysis, interviews with entities experienced in African contexts (e.g., Renken), and questionnaire answers provided by the municipality of Pikine Est reflect the existence of a negative influence of urban lacks and inadequacies in LQIs for the citizens of Pikine Est. This core problem is aggravated by the difficulty of allocating resources in peripheric cities in developing countries in order to remedy these lacks [9]. New ways of city planning must be proposed and additional LQIs have to be considered in these scenarios.

According to the literature, measuring LQIs in migrant countries induces the development of long term solutions [7,10-12]. The mentioned studies arrive at an assessment stage without going into project proposals. Therefore, they serve as a consolidated basis to acquire information on the current situation of migrants in diverse geographical contexts, where measured data is used as quantitative and qualitative references to describe actual scenarios, but does not necessarily account for the expected numbers and qualities these places should arrive at in order to improve. Other sources support the choice of targeting youth and women as key participants in urban level interventions, but do not develop direct strategies to involve them directly [13]. To merge both limitations, this study worked with youth and women through societal, technical, environmental, and economic components to prepare migrant communities for the future challenges they are expected to face by adapting already verified methods of urban planning [14].

Incremental urbanism, or incrementalism, is becoming a ground gaining concept in recent years as a city planning and building strategy, parting from the premise of conceiving city building at a much more personal and cost restricted scale, as opposed to large master plans, designed in a top-down fashion $[15,16]$. Focusing much more on a community approach, this line of thinking had already been used in the past but was then replaced by extensive city planning and intervention [14]. By targeting community needs using feasible economic budgets, incremental urbanism could be readapted to current times to become a viable alternative to address urban lacks: more changes with fewer resources and costs and promoting good practices at a social, economic, and urban level. Further advantages can be achieved when thinking ahead in time in the specific case of developing communities: if designed properly, these interventions can respond to the environmental challenges that the large metropolises worldwide already face today. This way, peripheric and "rurban" communities can be propelled into wider economic fruition of environmental services, generating opportunities in site as a result. Additional documentation supporting the idea of "thinking ahead in time" and developing the concept of "rurban" communities and environmental services can be found in Dr. Janis Birkeland's "Eco-positive design: Moving beyond ecological restoration" [17].

Conceiving urbanization under these new lines of thinking allows for the existence of a multiplicity of future scenario proposals. Taking as a priority the consideration of economic and human resources available, an accurate selection of LQIs and incremental urbanism indicators is pertinent to measure under new parameters the performance of feasible project scenarios [17]. Therefore, decision aiding processes must also be included. 
As a result, the goal of the present study was to analyze urban scenario proposals that part from incremental urbanism principles as means to create opportunities for youth and women in the area of Pikine Est. Additionally, under a pertinent indicator selection, these proposals were evaluated and outranked through multi-criteria analysis (MCA), presenting a new way of including and assessing incremental development indicators in "rurban" communities. MCA assesses the quality of an intervention based on preference factors and gives it a score among other scenario proposals [18]. Its application for the assessment of incremental urban planning project scenarios is innovative in the developing community planning sector [19].

A proposed methodology presented in Section 2 is used to answer a general question: "How can an urban proposal be deemed as the most convenient among a certain range of scenarios designed for a community with a strong vocation for emigration?" Section 3 demonstrates and discusses the final results, revealing the benefits of applying and assessing incremental urbanism principles in developing communities as a response to the initial research question. The paper ends with conclusive remarks and some recommendations for future urban planning projects in developing communities (Section 4).

\section{Materials and Methods}

Incremental community planning requires interventions in several sectors to establish a dialogue between planners and inhabitants as one of several strategies to avoid top-down master planning. To address such a complex issue, this study followed an integrated approach, proposed as a tool to help allocate resources for cooperatives in developing countries [9]. This tool was selected as an initial starting ground due to its applicability in African contexts and its alignment towards achieving certain Millennium Development Goals (MDGs). The innovation of its application in this study lies in the incorporation of MCA tools and methods as well as the consideration of diverse sectors and disciplines (i.e., integrated approach) during each project stage.

Although incremental urbanism is not an innovative strategy for city building on its own [14], its application in developing communities and therefore its fusion with integrated, cross-sector, multi-criteria, and multi-actor approaches is an absolutely novel approach [19]. In the scenarios developed in this study, the integration was conducted at technical, environmental, economic, and societal levels as a key element to performing proper planning, pertinent in developing communities today. This lead to the possibility of involving stakeholders with different backgrounds and interests in the urban scenarios' formulation and evaluation.

Understandably, stakeholders and strategies are likely to vary even within African contexts. The proposed methodology was decomposed into three project stages consisting of sequential steps, which individuated the project's target group and stakeholders from the very beginning. Joint work between them and the application of research methods [20] provided the necessary basis for strategy formulation. In this way, the methodology can be tailored according to each context by following one comprehensive guideline without compromising project success in any case [21].

\subsection{Research Framework}

In order to better understand the research process involved, this section breaks down the main methodological elements within the framework of integrated planning [9].

As it is shown in Figure 1, the methodological framework consists of threefold stages: (i) project identification, (ii) project formulation, and (iii) project evaluation, which is defined according to $[9,19]$. 

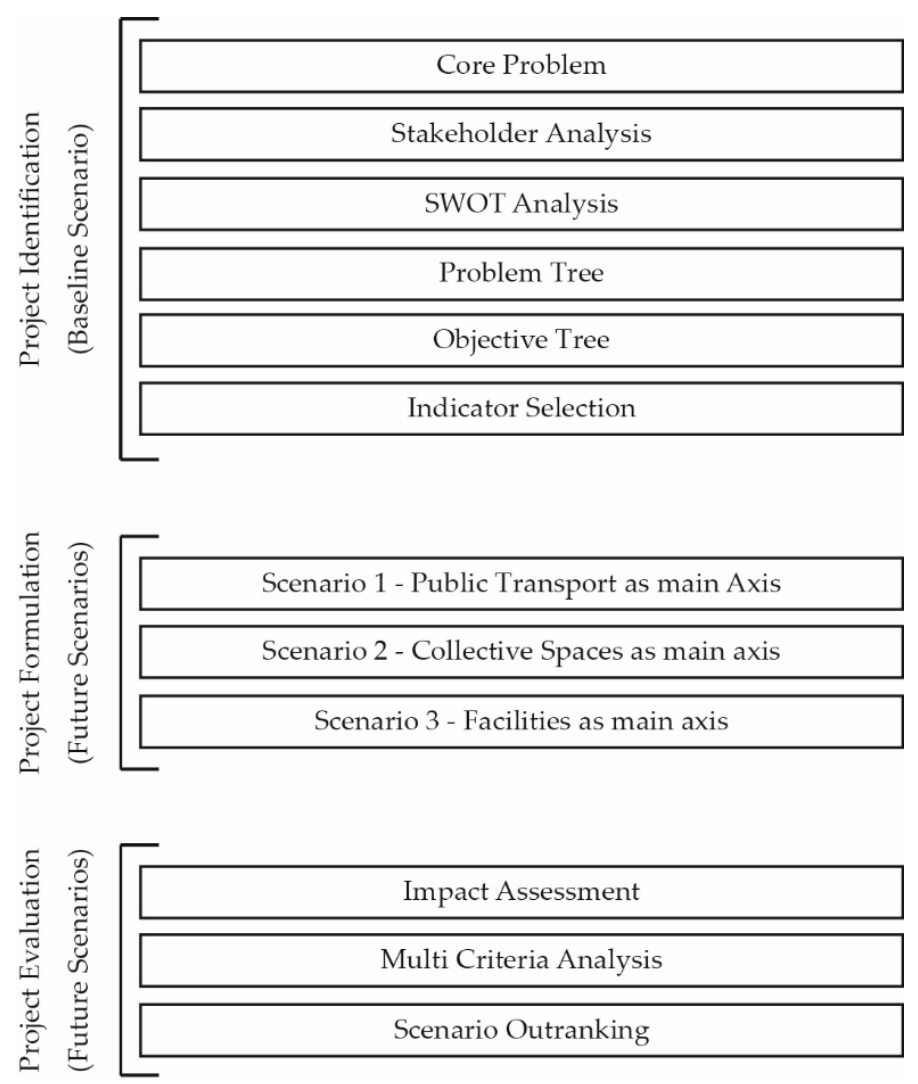

Figure 1. Methodology scheme.

The first stage, project identification, analyzed the present status of the city and its inhabitants, identifying through research and the literature review which target group to involve and which stakeholders to address. For this study area, the main stakeholders involved were the citizens of Pikine Est, the local municipality, and the Pino Torinese-Pikine Est project partners [22], while the target group was composed of youth and women in Pikine Est, being the most prone to irregular migration and the most vulnerable on a social aspect respectively [23]. Once a dialogue between a context's target group and project stakeholders had been established, project strategies could be refined and goals and objectives could be traced [24]. An accurate goal assessment requires indicators [4,5,25]. These indicators were distributed according to aspects and macro groups as a sort of guideline of bullet points a project scenario must consider to achieve traced objectives. Indicators came from a primary selection from the literature regarding both the general and the specific context. They later underwent filtering processes to extract those most pertinent to the study area according to suggested parameters [26]. As an outcome, it was possible to obtain the most accurate project decisions to launch a second stage, project formulation. This stage focused on the major urban and social gaps of the context at hand and transformed them into future project scenarios. The third and final stage, project evaluation, presented the procedure to select the best project scenario out of those proposed, using the indicators selected for evaluation in the second stage, also known as key performance indicators (KPIs), and MCA.

\section{Project Identification Stage}

This stage established the baseline scenario, meaning that it contains the necessary information and elements to describe the current situation of the city. Setting up a baseline analysis was a significant aspect in determining the future project proposals and the location of the hotspots. It was divided into six main methodological steps as follows.

1. Core problem: presented a diagnosis of the "symptoms" that affect the study area. 
2. Stakeholder analysis: assisted in the drafting of activities to be executed in order to know how and who to assign them to. The stakeholder analysis also pointed out who is more affected by problems, both those that the project seeks to resolve as well as those that threaten the project.

3. SWOT analysis: accounted for the social purpose of this project. This SWOT Analysis focused on the target group to identify the population's strengths, weaknesses, opportunities, and threats.

4. Problem tree: studied a core problem from its causes (represented as the tree roots) and effects (represented as the upper part of the tree).

5. Objective tree: corresponded to the problem tree. This tool transformed the core problem into a desired scenario, the causes into objectives, and effects into impacts.

6. Indicator selection: selected the most relevant indicators. Once the project's objectives had been defined, and base research had been conducted, the scenario proposal stage required methods for verifying its real estimated impact. As a result, the chosen methodology foresaw the selection (intentional choice of words, as indicators are not invented or created, only selected by previously established criteria.) of KPIs. These helped in settling measurable outputs for the project performance and examining their feasibility. Out of a large list of potential indicators, only a few were selected as KPIs based on their data availability, pertinence to the study area and target group, the stage in which they had to be measured (discarding for instance indicators that had to be assessed during project monitoring stages, which are not a part of this study), and the time required to collect the necessary data for their measurement.

Likewise, as explained previously in this study, aiming for the improvement of LQIs proves essential in facing irregular migration $[1,5]$. For this reason, this final methodology step involved a literature review to examine previous work conducted on this subject in order to adequately structure an indicator matrix within LQI principles. A literature review on authors discussing LQIs demonstrated that indicator frameworks are often classified in three main aspects (macro groups that label indicators under thematic categories $[3,5,27,28])$. Generally, this framework was divided into (i) physical, (ii) social, and (iii) economic aspects. This framework provided a base supported by several other authors in project decisions regarding indicator selection and classification within the limited amount of time available for its realization. The present study extended the framework to (iv) incremental aspects, conceived as a supplement for mainstream LQI aspects such as those previously numbered. The incremental aspect acted as a fourth category that covers endemic problems related to environmental services (functions performed by natural air, water, and land assets [29]) and social paradigms to be assessed within a specific context. The motivation behind this was to prove that incremental issues also alter life quality, especially in developing communities. Likewise, introducing incremental community planning as an aspect linked to quality of life and assigning macro indicators to assess it is part of the novelty and core of the proposal of this study.

Project Formulation Stage

This stage parted from the conclusion of the previous stage, where KPIs were selected. The baseline scenario documentary analysis and research indicated the critical elements in urban life in the study area in order to adequately choose and implement efficient strategies to improve LQIs in the area. The results of this process were later manifested in future-oriented scenarios. These scenarios, accounting for the lack of resources in the context of developing communities, revolved around one main axis of intervention each, using specifically chosen strategies that incorporated incremental community planning principles to reduce financial requirements. By addressing the community's main gaps directly, these proposals effectively promoted improvement in LQIs for the study area.

\section{Project Evaluation Stage}

The last stage intended to select the best project scenario according to the selected KPIs, previously selected in line with project objectives. In this stage, the methods used to calculate each KPI were presented, and the most fitting urban scenario proposal was obtained through outranking methods. The methodological steps presented in Figure 1 for this stage are detailed below: 
1. Impact assessment: This step analyzed the selected KPIs for future scenarios. The main information was collected for each indicator, such as intent, assessment methodology, description, data requirements, and sources.

2. Multi-criteria analysis: A starting base was selected for outranking evaluation, confronting KPIs' calculation results, and organizing them from best to worst.

3. Scenario outranking: the PROMETHEE (preference ranking organization method for enrichment evaluation) methodology was employed to outrank the scenarios with the support of preference functions and performance and impact matrices. Discussion regarding the best scenario concludes the methodology stages.

\subsection{Study Area}

Pikine Est was selected as a pilot study area, located in what was formerly known as the peri-urban area of Senegal's capital, Dakar [30]. After the Act of Decentralization of 2013, Pikine Est became a neighborhood within the municipality of Pikine, independent from Dakar (see Figure 2).
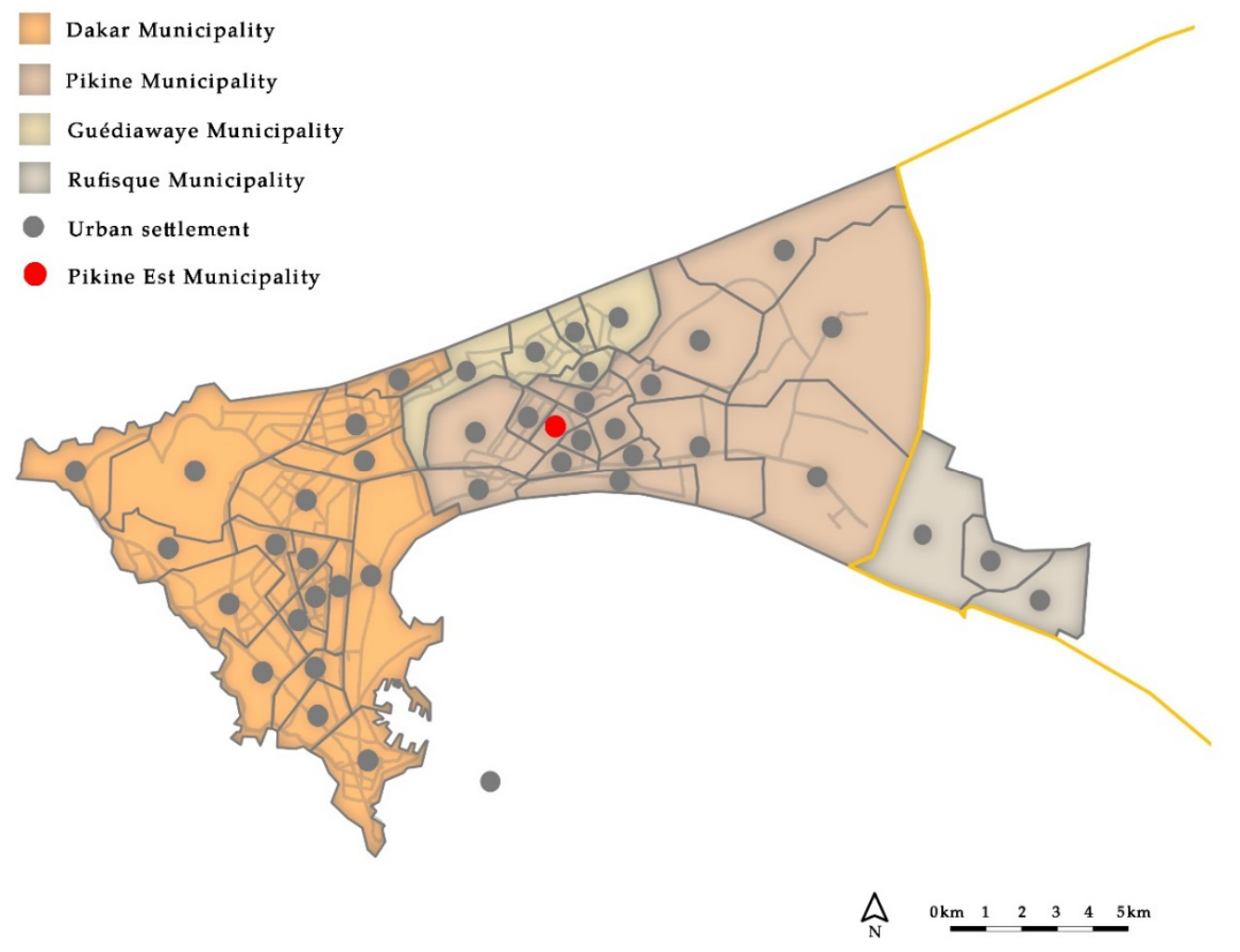

Figure 2. Territorial Division of Dakar, Pikine, Guédiawaye, and Rufisque, re-elaborated based upon [8] (Carte 2).

The story of Pikine Est goes back as far as 1952, when construction began for peri-urban areas. High occupation rates at the Cape Vert Peninsula and an increasing need for space to continue growing were the two detonators that set into motion the displacement of people occupying irregular properties around Dakar [1,31]. These families were then relocated in the zones considered back then as the outskirts of the capital. Many negative situations were generated as a result, from the most obvious one being uncontrolled urbanism, going as far as social resentment from inhabitants in peri-urban segregated areas toward those in the capital [32].

With an estimated population density of 42,144 inhabitants per square kilometer [33], Pikine Est is a high density and mostly residential neighborhood. Growing without regulations has led the area to expand in isolation from Dakar (several people in Pikine have never even been to Dakar) 
(this enunciation is taken from one of the answers included in a questionnaire sent to the Pikine Est municipality through the Pino Torinese committee) with a scarcity of "green" public zones and lack of cultural hubs. The situation is aggravated by the fact, for instance, that the average household in Pikine is composed on average of seven members [11]. Land use distribution demonstrating the large predominance of residential use is presented in Figure 3.

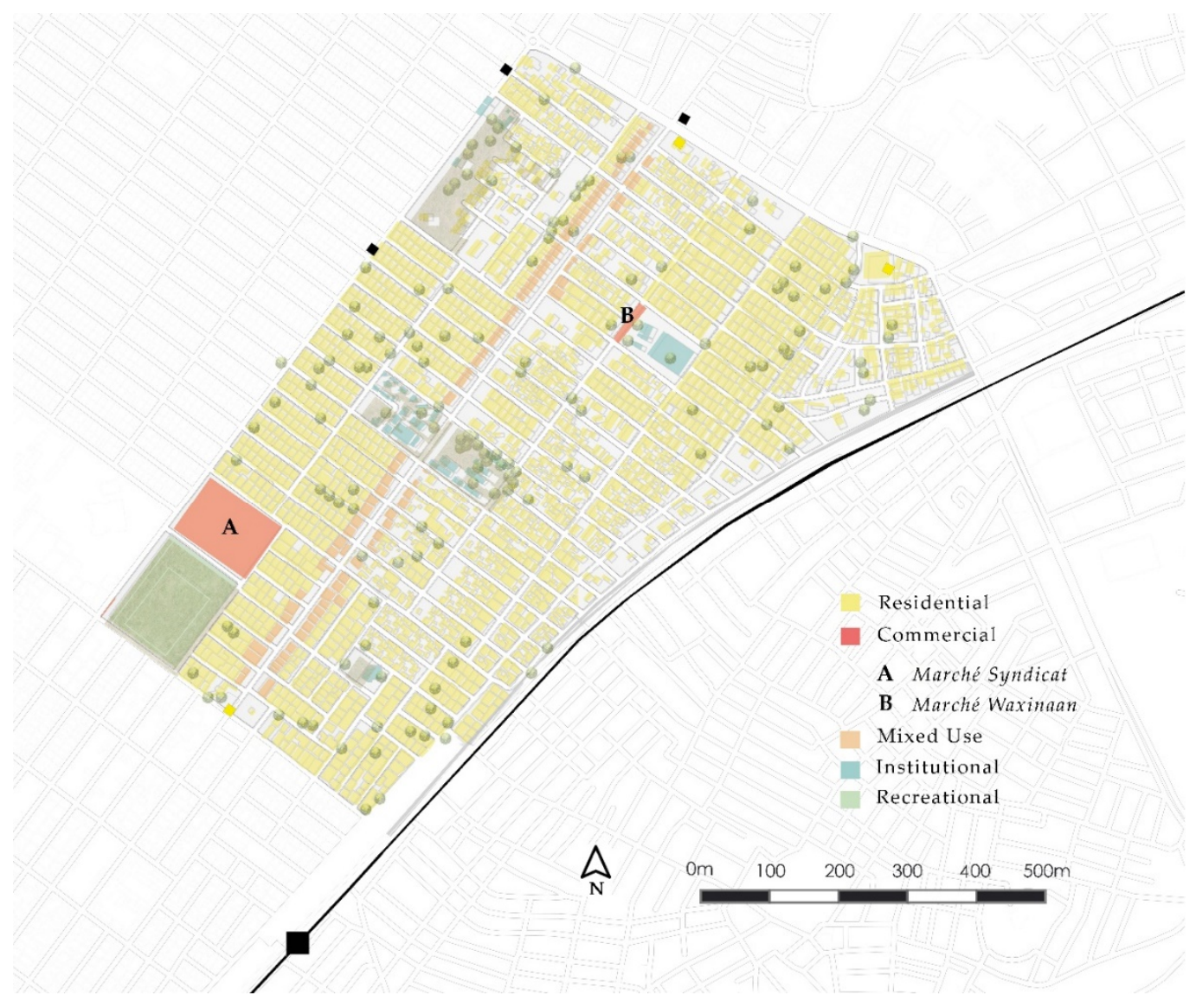

Figure 3. Land Use Map for Pikine Est, re-elaborated based upon information from [22,34].

As shown in Figure 3, in the center of Pikine Est, people can find the town hall, one cinema (Cinema Awa), a school, and the new sports area built in 2019 together with the municipality of Pino Torinese as a result of the decentralized cooperation project. Another sports area, composed of a large soccer field and a smaller basketball field, may be identified to the south of the municipality. The urban layout is also completed by two large open-air markets and three other educational facilities, with the rest being mostly occupied by residential and mixed land. On a more specific level of detail, it is possible to identify educational, medical, cultural, religious, and sports facilities, as well as individual businesses in Pikine Est.

This area is occupied primarily by young dwellers: $3 / 4$ of the total population of Pikine Est is composed of people below 35 years of age [22]. Research on migratory patterns matches with this data: out of three separate age groups (0-14 years old, 15-39, and 40-60 and over), the one most prone to migrating corresponds to the $15-39$ year old group, making up $72.1 \%$ of the total data collected [12]. Their main motivations to migrate include work (73\%), study (12\%), and family (7\%).

Although the population in Senegal is almost equally distributed among men and women (i.e., $49.8 \%$ for the former and $50.2 \%$ for the latter), and so are the numbers regarding irregular migration [35], research conducted on the returning migratory flows (amount of people that voluntarily reenter the country after having emigrated from it) reveal uneven data: out of all the women that leave the country, only $3 \%$ return after searching for better opportunities elsewhere [35]. Possible motivations 
behind this phenomenon may be found in UNESCO's Global Partnership for Girls' and Women's Education report [23]. The main data drafted from it reveal differentiated adult (fifteen years old and over) literacy rates (i.e., $62 \%$ for men and $39 \%$ for women) and low gender parity in education (e.g., secondary education enrollment percentage for men is $34 \%$ and $27 \%$ for women [23]). Some reasons behind this data include early marriage, teenage pregnancy, and gender-based violence [23].

As one of the objectives of the project, it is also important to detain on household waste management data. Diawara [11] includes in his work a study conducted on the soil (to determine its quality), which estimated the average amounts of common household waste materials, measured in grams per square meter. This gives an idea of which is the most common type of waste and the consumption patterns in Pikinese families (knowing from the same source that, on average, one person in Pikine produces $0.68 \mathrm{~kg}$ of household waste per day), and it also offers insights on which are the most common activities generating this waste. Data collected by Diawara can be seen in Figure 4.

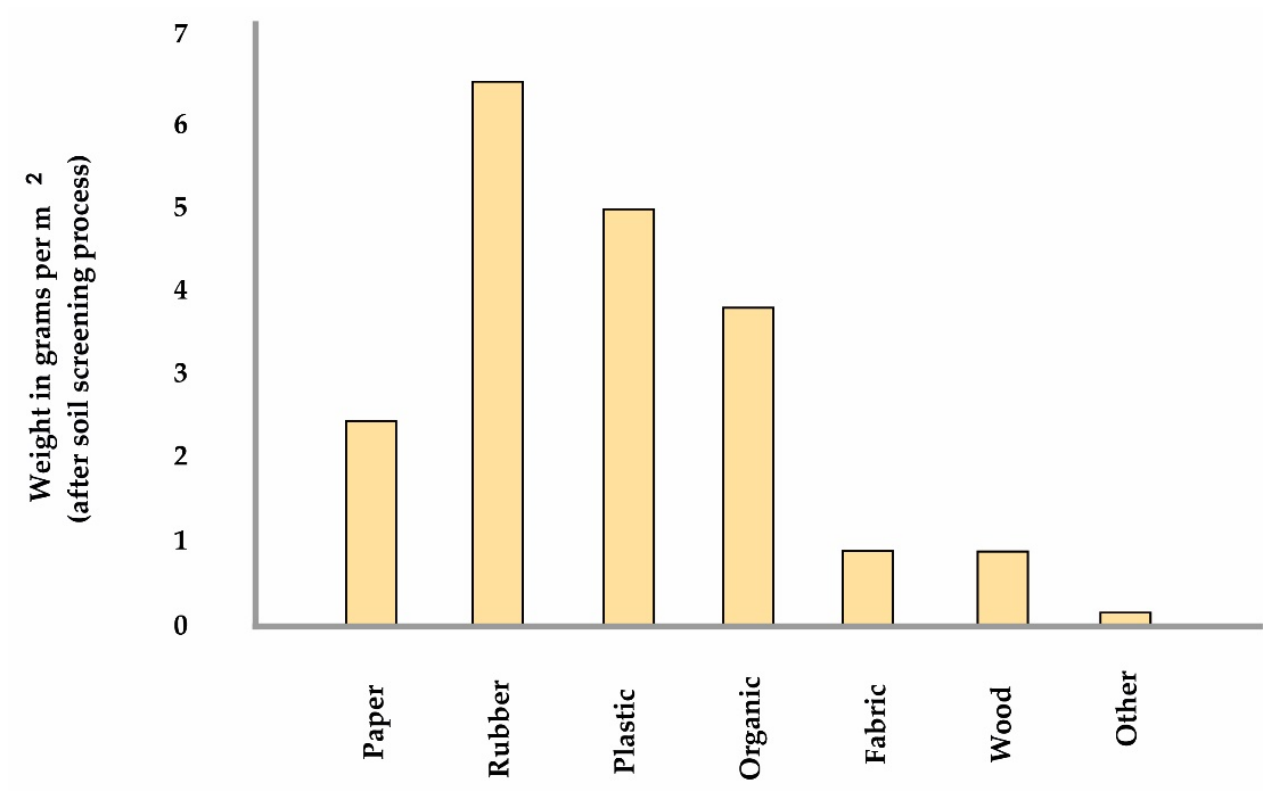

Figure 4. Weight of household waste materials from soil screening processes, re-elaborated based upon [11] (p. 170).

Most of Dakar's peri-urban area is built over soil-sealed land. This means that wetlands have been artificially covered with soil to create new land to build, as near as possible to the city center, one usual sign of overcrowding. This is the recipe for high vulnerability to natural hazards. According to Wang et al. [30], these hazards have been classified into coastal erosion potential, flood potential, and coastal inundation potential (divided into $1 \mathrm{~m}$ and $5 \mathrm{~m}$ rise of the sea level). Likewise, these hazards are evaluated and assigned with a risk level: none, low, moderate, and high. Figure 5 shows the built versus non built ratio for urban, peri-urban, and rural areas in the Dakar territory. It is important to recall that, being elaborated before the Act of Decentralization of 2013, this document still uses the "urban", "peri urban", and "rural" territorial classifications. Today, these would be divided into the Dakar municipality, the Pikine and Guédiawaye municipalities, and the Rufisque municipality correspondingly. It also presents the expansion of each zone according to the proportion of constructions settled in no- or low-risk potential zones and those settled in moderate- or high-risk potential zones over the course of ten years. Results evidence unregulated hazardous growth in the peri-urban area, the sector of interest for the study area. 


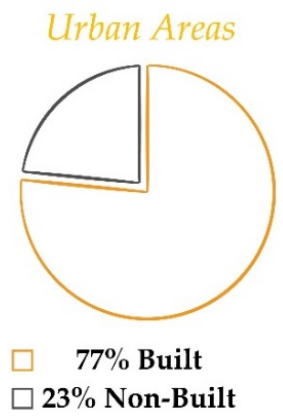

Urban Areas

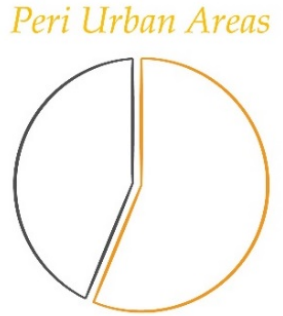

$55 \%$ Built $\square 45 \%$ Non-Built

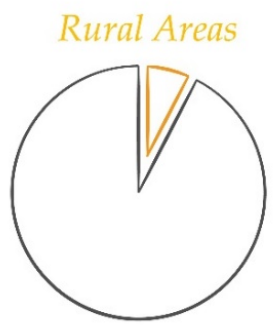

$6 \%$ Built

$\square \mathbf{9 4 \%}$ Non-Built

\section{Peri Urban Areas Rural Areas}

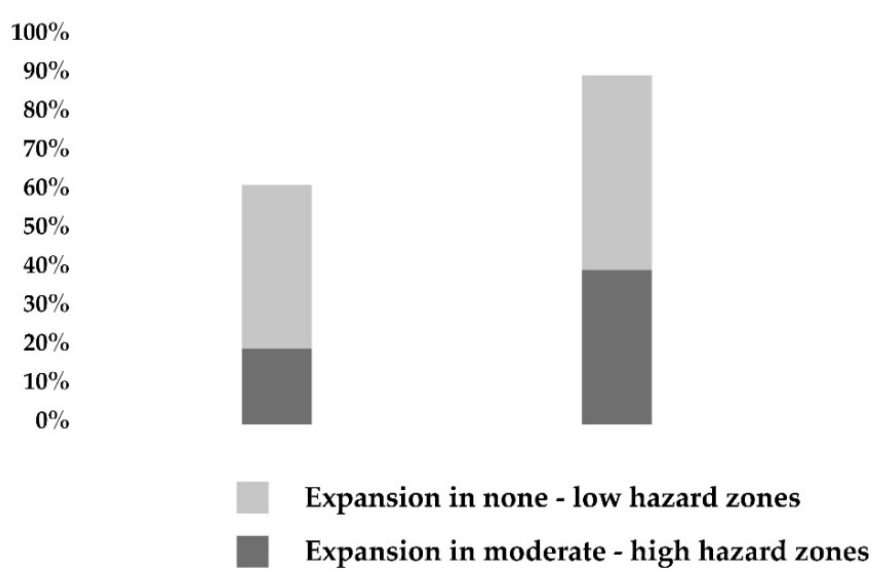

Figure 5. Built vs Non-Built areas in 2008 - Expansion in Hazardous Areas between 1998 and 2008, re-elaborated based upon [30] (p. 58).

\section{Results and Discussions}

\subsection{Project Identification Stage}

Born as a result of methodological research and study area selection, the core problem that best describes the symptoms that afflict Pikine Est is the negative influence of urban lacks and inadequacies in LQIs for its citizens. This main problem was first studied through a SWOT Analysis, which defines project strategies that work together with the group's strengths and create plans of action to mitigate weaknesses and remedy threats. It is worth recalling that strengths and weaknesses are internal within the target group, while opportunities and threats constitute external factors. The analyses suggest that it would be useful to take advantage of Pikine's cultural mix in order to best merge rural tradition with urban innovation. This could later become a strategy to create a sense of social well-being through the diffusion of the project by its own inhabitants, and it could enrich following decision-making stages with stakeholders. On the other hand, through this methodological tool, it was also possible to conclude that the project must seek to remedy a culturally marked gender gap, part of the target group's weaknesses.

Afterwards, a problem tree structured the core problem. By addressing the causes that generate it, hypothetically, the project was able to revert these situations, and eventually mold the problem into a scenario, examined later in the objective tree. Causes for the core problem identified include high population density in an area with scarce common/green areas, gaps in educational basis for the youth (such as illiteracy and scholar abandon), and inadequate spatial conditions for cultural diffusion and teaching. Naturally, the effect of the core problem itself is the high amount of people opting for irregular migration. 
The objective tree integrated what the project in its entirety must comprise and showcased the ideal conditions that need to exist in order to arrive at an ideal scenario. Causes were reverted and project objectives were obtained as outputs. In this case, these objectives included assigning areas for densification as well as common areas, providing schools with the lacking infrastructures (in the area, many lack proper canteens and sanitary installations [32]), and creating spaces for cultural diffusion.

The first set of indicators is shown in Table 1. Each aspect contains macro indicators commonly used to address life quality. This study presents only those which are pertinent to the study area, as LQIs are extensive and vary in their applicability according to their context [4]. Indicators were selected within each macro group under the same criteria.

Table 1. First Set of Indicators.

\begin{tabular}{|c|c|c|c|}
\hline ASPECTS & MACRO INDICATORS & INDICATORS & SOURCE \\
\hline \multirow{11}{*}{ PHYSICAL } & \multirow{5}{*}{ STREET CLEANLINESS } & Cost of service per household & \multirow{5}{*}{ [36] } \\
\hline & & User satisfaction & \\
\hline & & Workforce costs & \\
\hline & & Transport costs & \\
\hline & & Percentage of waste recycled & \\
\hline & \multirow{2}{*}{ QUALITY OF THE ROADS } & Environmental impact & \multirow{2}{*}{ [37] } \\
\hline & & Green corridor control & \\
\hline & HOUSING & Population density & [38] \\
\hline & \multirow{3}{*}{ PUBLIC SPACE QUALITY } & User satisfaction & \multirow{3}{*}{ [39] } \\
\hline & & Cost of management per resident & \\
\hline & & Customer requests for street trees and parks & \\
\hline \multirow{12}{*}{ SOCIAL } & \multirow{2}{*}{$\begin{array}{l}\text { QUALITY OF SERVICE } \\
\text { FACILITIES }\end{array}$} & Availability and proximity & \multirow{2}{*}{ [25] } \\
\hline & & Total GHG emissions from primary energy & \\
\hline & \multirow{5}{*}{ WASTE MANAGEMENT } & Saturation rate & \multirow{5}{*}{ [40] } \\
\hline & & Percentage of reusable waste & \\
\hline & & Percentage of waste reused in-site & \\
\hline & & Cost of service per household & \\
\hline & & Transport costs & \\
\hline & \multirow{5}{*}{$\begin{array}{c}\text { PUBLIC } \\
\text { TRANSPORTATION }\end{array}$} & Cost of the fares & \multirow{5}{*}{ [41] } \\
\hline & & Environmental Impact & \\
\hline & & Service availability & \\
\hline & & Comfort & \\
\hline & & Service performance & \\
\hline \multirow{2}{*}{ ECONOMIC } & \multirow{2}{*}{ INCOME } & Quantity of jobs created & \multirow{2}{*}{ [42] } \\
\hline & & Investment costs & \\
\hline \multirow{9}{*}{ INCREMENTAL } & WATER MANAGEMENT & Recharge of groundwater & [25] \\
\hline & ITEPACY & Facility capacity & \multirow{2}{*}{ [43] } \\
\hline & LIIENAC & Condition of the facilities & \\
\hline & \multirow{3}{*}{ BIODIVERSITY } & Surface of recovered habitats & \multirow{3}{*}{ [44] } \\
\hline & & Impact on local species & \\
\hline & & Freshwater quality & \\
\hline & \multirow{3}{*}{ HERITAGE } & Level of participation & \multirow{3}{*}{ [45] } \\
\hline & & Quality of the interventions & \\
\hline & & Level of "artealization" & \\
\hline
\end{tabular}


The most relevant indicators were filtered based on specific criteria (i.e., data availability, pertinence to the study area and target group, stage in which they are assessed, and time required for their assessment [26]) and extracted from the first list of indicators (Table 1). The final KPIs were population density, waste containers' average saturation rates, public transportation service performance, recharge of groundwater, and literacy facility capacities, as seen in Table 2

Table 2. Final list of KPIs.

\begin{tabular}{cccc}
\hline ASPECTS & MACRO INDICATORS & INDICATORS & SOURCE \\
\hline PHYSICAL & HOUSING & Population density & {$[38]$} \\
\hline \multirow{2}{*}{ SOCIAL } & WASTE MANAGEMENT & Saturation rate & {$[40]$} \\
\cline { 2 - 4 } & PUBLIC TRANSPORTATION & Service performance & {$[41]$} \\
\hline \multirow{2}{*}{ INCREMENTAL } & WATER MANAGEMENT & Recharge of groundwater & {$[25]$} \\
\cline { 2 - 4 } & LITERACY & Facility capacity & {$[43]$} \\
\hline
\end{tabular}

Among the initially selected indicators, 11 were suppressed due to scarce data availability, 10 due to the stage of assessment (removing those that may only be verified at a project monitoring stage), 7 due to the extensive time requirements for calculation, and 1 due to the non-pertinence to the study area and target group as, as explained in Section 2.2, different services have adequate coverage, availability, and proximity to reach most of the population of Pikine Est.

Incremental indicators considered here affect the study area today, but they are also likely to be applicable in other African contexts assessment tools for quality of life [46]. For instance, water management is a tendential issue in developing communities due to lack of sanitation networks and proper water drainage when it comes to coastal cities and constructions over soil-sealed land. As examined in Section 2.2, literacy is another key element to address, usually accompanied by gender gaps, where men have higher literacy rates than women, reducing the equity in opportunities [23]. Biodiversity may naturally involve strategies more specific to each context, changing according to the environment of each developing community, although its indicators may still be applicable in different cases. Reduction of biodiversity may affect local small and large economies [47]. Assessment tools and strategies to promote heritage should also be included, as increasing the common sense of belonging is a proper way to sponsor economic and social growth within the community by its own inhabitants [45].

Additionally, it is imperative to clarify the concept of "artealization" introduced by [45], which relates to the different ways in which citizens appropriate a public space with a specific heritage connotation. This is a pertinent concept to introduce in urban design, incentivizing creativity in the usage of public spaces through visual arts, music, literature, and performances [45].

\subsection{Project Formulation Stage}

Research, discussions, indicators, and strategies take shape in urban interventions, rooted in smaller-scale (incremental) actions which lead to cyclic progress toward a large-scale change in favor of the community. As we were aware of the limitations, mostly in the financial aspect, that such interventions might face in this spatial context, they were separated into three scenarios. Each intervention scenario proposed or adapted strategies around one of the lacking branches of urban life identified in Section 2.2: transportation, collective spaces, and service facilities. By identifying these macro-areas of intervention to focus on, future scenarios were composed of punctual strategies that point toward the improvement of a wide-scale element or activity within the urban grid of the study area. It is therefore natural that these macro-areas or branches vary between contexts. However, their individuation is of the essence at a project formulation stage in developing community scenarios to assist in project feasibility.

The project strategies were the result of the method's application in the study area. An adequate application of an incremental project strategy should point towards short term improvement of 
conditions through inhabitant participation and involvement using low resources. For instance, large infrastructural solutions to the water management issue in Pikine Est such as those proposed in [48] cannot be considered as incremental strategies. However, institution strengthening and community awareness on the matter [48] may be conceived as incremental actions, promoting consciousness for better behaviors using few financial resources.

As stated previously, strategies are bound to vary under different conditions, not denying however a possible replicability amongst them. It is essential to clarify that the division of scenarios does not mean that strategies cannot intersect in more than one scenario; it simply means that the chosen strategy set works best when applied in its corresponding scenario. In fact, one of the main reasons to conduct a project evaluation and assessment through MCA methods is interest in determining which are the best strategies to apply in the study area. These tools and methods should be used as means of recognition of a scenario's incremental factor and effective LQI improvement, assessed in terms of each study's selected KPIs (presented in this study in Table 2.

To achieve the goal of creating opportunities for youth and through incremental urbanism principles, the project scenarios mixed strategies as follows (These explanations can be compared to the graphic material included in the Appendix A).

Scenario 1. Public Transport as main axis: Parting from a core intervention consisting of the displacement of the nearby Petit Train Bleu station to a closer point in the area, this scenario foresees the revitalization of pedestrian and vehicular roads connected to the station's new location. Today, many small-scale businesses bloom within the neighborhood, but the lack of proper infrastructure is their most common challenge. As a result, all three project scenarios propose the application of modular spaces built from economic yet durable materials in efforts to optimize and structure these commercial activities and to be placed along these "commercial axes". These activities currently go from fruit sale stands to furniture selling kiosks. A similar discourse regarding the creation of "revitalized commercial axes" is applied when determining the location of new bus stops. This strategy is applicable to the following two scenarios, where stops are built using local materials (e.g., wood, recycled rubber from tires). In this way, bus stops can also reduce costs, while allowing for easy dismantling should it be required at a project operational/monitoring stage. At a cultural level, this scenario foresees a secondary use of Cinema Awa as a cultural hub and the requalification of the existing Maison de la Femme as an alphabetization facility with courses held by women in the community.

Finally, each scenario tests different options for densification. Habitational typologies are taken from "50 Urban Blocks" [49]. These blocks include floor area ratios and coverages for each suggested volume. For all three scenarios, they are chosen by balancing the number of square meters they occupy with the quantity of space available for densification, composed by the area currently deemed as "irregularly occupied" [50] and additional blocks with poor states of housing consolidation. Once chosen, their calculations and volumes are adapted when needed in order to keep them at a maximum height of five floors to avoid disruption in the urban landscape.

Scenario 2. Collective Spaces as main axis: This scenario alternative suggests that well-kept spaces with a wide diversity of trees would play a key role as a strategy to attract higher flows of people. From this initial premise, other services are located in proximity to "natural corridors", designed to connect the study area with nearby natural bodies, such as the wetland to the north. Following the guidelines for feasibility from similar projects [51], these corridors will be reforested with lemon, mango, moringa, and jatropha trees. Responding to the consequent increase of shadowing (and therefore the creation of darker areas prone to insecurity), these spaces in the project will also incorporate lower tier light posts. As a secondary strategy, a new medical center is proposed on a plot where there is currently a gas station (abundant in the area), allowing the possibility to complement this section of green axis with commercial activities and exterior sale stands. The housing typology selected for this scenario prioritizes the creation of shared spaces within urban blocks. This proposes spaces that are a middle ground between private and collective property, meaning they are of common responsibility, hoping to begin the conscientization process at a smaller scale by slightly altering ways of inhabiting. 
Finally, at a cultural level, this scenario proposes using walls surrounding the soccer field to display famous personalities from Senegalese history, focusing on the relevance of heritage.

Scenario 3. Facilities as Main Axis: The main action featured here consists of joining Marché Syndicat with Marché Waxinaan and transforming them into linear markets. The spaces they currently occupy will then host the scenario's core structures: new medical and cultural centers will be built in the plot occupied by Syndicat, while Waxinaan will be moved to leave space for a workshop near the school grounds, which will supply the local educational facilities with the furniture they currently lack, according to the document from the Pikine Est municipality. Both activities are also addressed to increase the number of jobs on-site.

For each scenario, separate waste containers are placed in the inner spaces of the designated blocks, keeping them away from the sight of local passersby. Among the investment costs to be considered, it would be advised to include costs for information, covering the expenses required to let citizens know which days each waste container would be collected and how to separate waste. From the literature and research, it is possible to know there is a likelihood of finding discarded tire rubber in the study area, therefore allowing its reuse, in this case, as pavement material, providing an alternative to asphalt sidewalks and increasing ground permeability this way. Other strategies were considered to combat sea level rising and flooding events. These, however, were not included in the project formulation stage because, according to research, an optimal solution would require large-scale infrastructure costs, not pertaining to the Pikine Est municipality. These strategies can be found in the flood prevention and drainage project [48].

\subsection{Project Evaluation Stage}

After conducting assessment feasibility studies as selection filters, the final KPIs used for the project evaluation are population density, waste containers' average saturation rates, public transportation service performance, recharging of groundwater, and literacy facility capacities. As part of the impact assessment methodological tool, these KPIs will be briefly explained below.

- Population density (habitants $/ \mathrm{km}^{2}$ ): Estimates future demographic change brought along with each habitational typology proposed by the urban scenarios, establishing a ratio between the number of inhabitants within a surface area. High values are preferred for this KPI, under the concept of stimulating care for collective spaces proposed in each habitational typology. This KPI is also highly relevant, as its results for each scenario are used to calculate other following KPIs.

- Waste container average saturation rate (days): Estimates how often waste collection containers reach their maximum capacity. A service coverage ratio is established, making it possible to use population density calculation results to foresee the number of people using each container site. Data collected from Diawara [11] offers a daily amount of waste per inhabitant per household waste material. Using the material densities of each, it is then possible to calculate an average saturation rate. High-value results are preferred, suggesting fewer weekly trips needed for waste collection vehicles.

- Public transportation service performance (\%): Foresees the coverage public transport will offer for the community. It is calculated by obtaining the percentage of people living within a $400 \mathrm{~m}$ radius from any public transport station within the study area [25]. This category includes both bus and railway transport systems. High values are preferred, indicating better performance.

- Recharge of groundwater (ground permeability) (\%): Strategies to increase groundwater absorption as a response to flooding events include recycled rubber pavements as well as the creation and expansion of green areas. With each material's permeability coefficient, it is possible to calculate the new overall ground permeability percentages. Higher values are preferred, as higher ground permeability may mean better flood control.

- Literacy facility capacities (people): Calculates the maximum number of people that may simultaneously occupy the alphabetization structures. Obtained by dividing the effectively useful 
area of each facility, accounting for $15 \%$ of each for technical rooms and circulation, by the minimum area required for each occupant [52]. Higher values are considered positive, meaning that more people can benefit from the facilities at once.

The performance matrix presented in Table 3 displays the resulting values for each KPI following their assessment. For the KPIs used, a higher value is considered as a positive and desired value, whilst a lower value is negative.

Table 3. Performance Matrix.

\begin{tabular}{cccccc}
\hline SCENARIO/KPIS & $\begin{array}{c}\text { Population } \\
\text { Density } \\
\text { (hab/km }\end{array}$ & $\begin{array}{c}\text { Public Transp. } \\
\text { Performance (\%) }\end{array}$ & $\begin{array}{c}\text { Waste Container } \\
\text { Average Saturation } \\
\text { Rate (days) }\end{array}$ & $\begin{array}{c}\text { Ground } \\
\text { Permeability (\%) }\end{array}$ & $\begin{array}{c}\text { Literacy Facility } \\
\text { Capacity (People) }\end{array}$ \\
\hline $\begin{array}{c}\text { Scenario 1 } \\
\text { Public Transportation } \\
\text { Scenario 2 }\end{array}$ & 46,429 & 100 & 2.83 & 11.13 & 3187 \\
$\begin{array}{c}\text { Collective Spaces } \\
\text { Scenario 3 } \\
\text { Facilities }\end{array}$ & 46,097 & 78 & 3.16 & 14.76 & 2215 \\
\hline
\end{tabular}

Initial results could suggest a triumph of Scenario 1, excelling at two categories and failing only in one. However, there is no further support for this decision, as preference has not been established among KPIs. To counterbalance the limitation of not being able to contact all project stakeholders and establish said preference, Visual PROMETHEE was used as a decision-making software classified as an outranking method. The PROMETHEE method for this software began with the insertion of KPI assessment results. By assigning a preference for each result (indicating whether the desired value is the lowest or the highest), giving each a "quantitative" or "qualitative" assignation (all KPIs are quantitative for this study), and selecting a preference function (calculation method to determine how much is one alternative preferred over another), an Impact Matrix as created within the software.

For this study, the PROMETHEE method with "Linear" and "V-Shape" functions were assumed to be tailored to the nature of the criteria, as they are the most appropriate ones to treat quantitative indicators such as those employed to assess the project scenarios [19]. The remaining functions work best with qualitative information. The main difference between Linear and V-Shape is whether an indifference is accounted for or not, respectively. Indifferences ( $Q$ in PROMETHEE) are mostly applied when indicator results are widely different one from another, as they express which is the minimum value that a decision-maker would find negligible. Preferences $(\mathrm{P})$, on the other hand, stand for a value that would weigh on the chosen scenario. The preference function assistant featured in Visual PROMETHEE helps determine preferences and indifferences (when applied) in the absence of stakeholders or decision-makers. In the case of preferences, it does so by inserting the value of the difference between the highest and the lowest indicator value. For indifferences, it uses the standard deviation between the differences. Once the proper preference functions have been selected, Visual PROMETHEE can calculate the preference index, which represents the intensity of preference of one KPI over another, taking into account the weights assigned to each. For this study, all KPIs were assigned with equal weights, for this is a decision to be discussed extensively with project stakeholders.

Finally, the preference index was used in Visual PROMETHEE to calculate outranking flows, divided into two kinds: leaving flows (i.e., the "positive" ranking for each scenario, represented as "Phi+" in Table 4) and entering flows (i.e., the "negative" ranking for each scenario, represented as "Phi-" in Table 4). The net flow was conceived as the determining outranking result, obtained by the difference between outranking flows. Results following MCA application are shown in Table 4.

Remarkably, these results show the radical triumph of Scenario 2, focused on strategies for Collective Spaces, over the other two alternatives. It is of the essence to remark that this decision is the result of evaluation including only five KPIs and is not under any circumstance implying that it would be the most successful of all interventions if they were to be implemented. As mentioned before, this evaluation shows the best combination of strategies applied in the project formulation stage. 
Nonetheless, it is possible to observe how, out of all five KPIs tested, Scenario 2 was first in only one (waste container saturation rate), while the other two scenarios each ranked best in two categories each. This proves the usefulness of PROMETHEE methods in the assessment of incremental urban planning project strategies, as the results displayed in Table 3 do not act as a proper evaluation able to provide support in choosing an ideal scenario. Graphic material produced to represent Scenario 2 proposals is shown in Figures 6-8. Proposals for Scenario 1 and Scenario 3 are included in the Appendix A.

Table 4. Outranking Results.

\begin{tabular}{ccccc}
\hline Rank & Action & Phi & Phi+ & Phi- \\
\hline 1 & Scenario 2 & 0.1368 & 0.3459 & 0.2091 \\
2 & Scenario 1 & -0.0562 & 0.2939 & 0.3501 \\
3 & Scenario 3 & -0.0805 & 0.2854 & 0.3660 \\
\hline
\end{tabular}

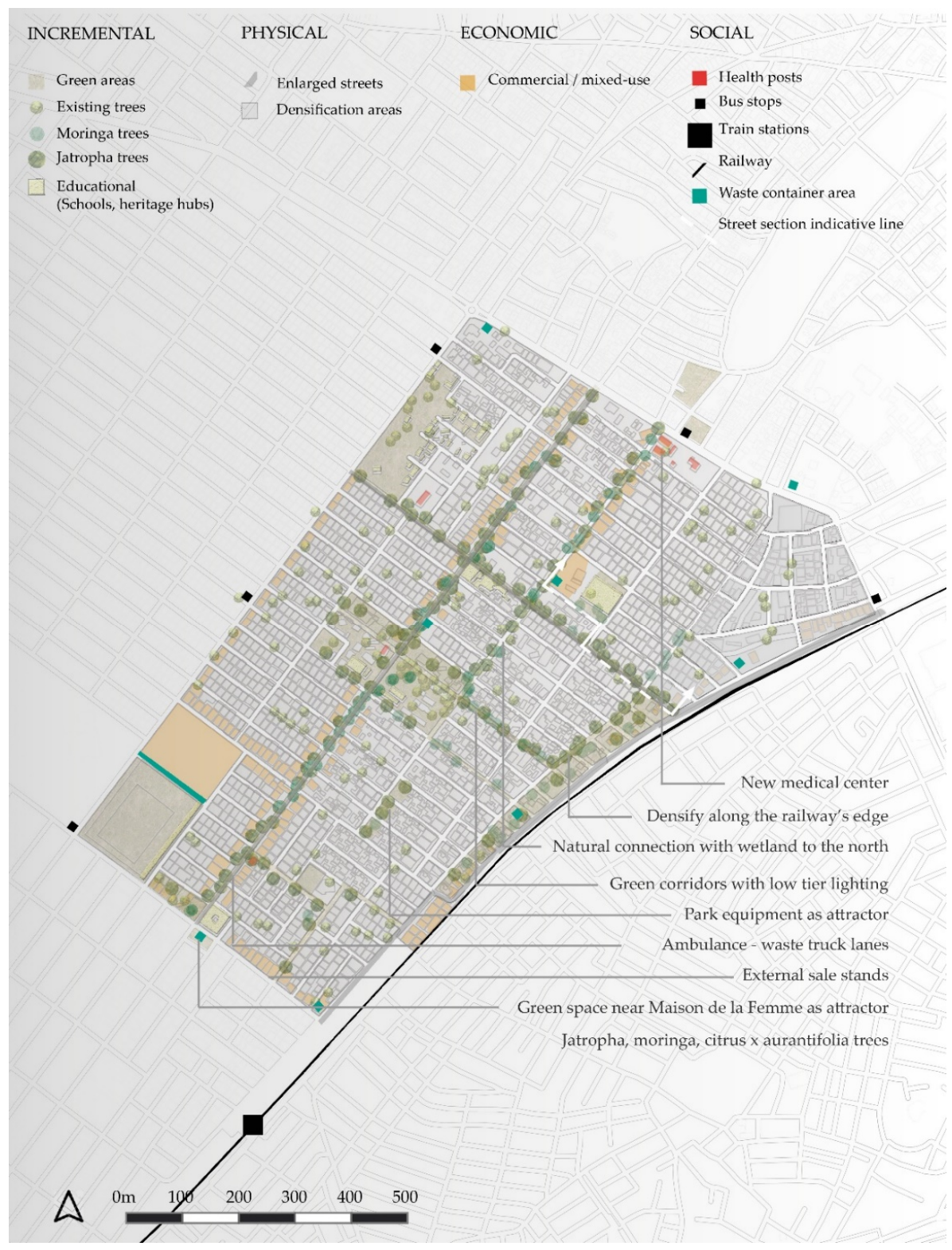

Figure 6. Intervention plan for Pikine Est according to Scenario 2. 
INCREMENTAL

Water Management

Literacy

Biodiversity

Heritage

PHYSICAL

Street Cleanness

Quality of the Roads

Housing Quality

Public Space Quality

\section{ECONOMIC}

Income

\section{SOCIAL}

Public Transport

Waste Management

Quality of the Facilities

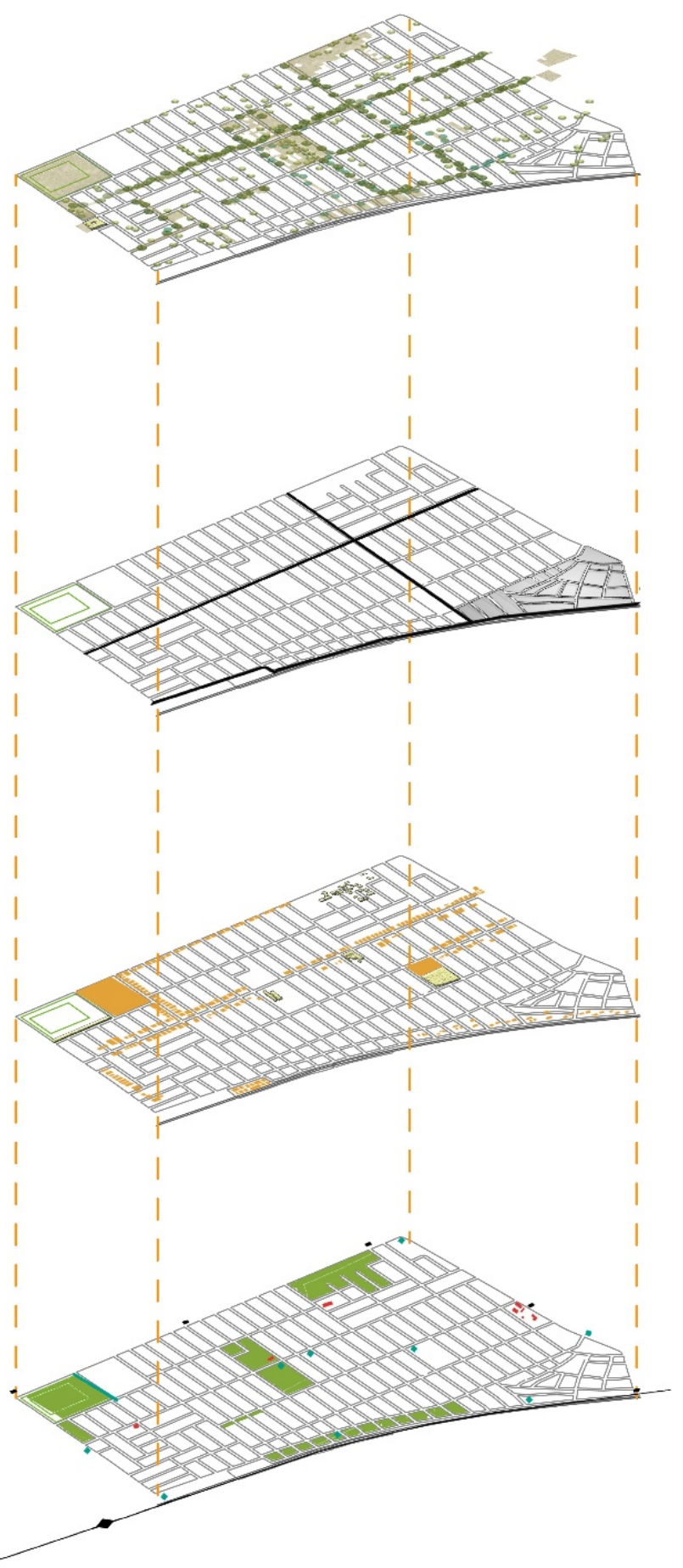

Figure 7. Exploded layers of site intervention for Scenario 2.

Result examination cannot be limited only to the highest-ranking scenario, but must also include the lowest. Doing this brings attention to the outranking results of Scenario 3, obtaining the best KPI results within the incremental aspect KPIs (facility capacity and ground permeability: see Table 3) but ranking last after conducting MCA. Although this might seem contradictory to the study's claims at first, it is mainly due to weight assignation. Initially, all LQI aspects included in this study were assigned with equal weights; PROMETHEE makes no distinction amongst them. Therefore, scenario 3 ranks last despite excelling in the incremental aspect. 
Fix Strategies

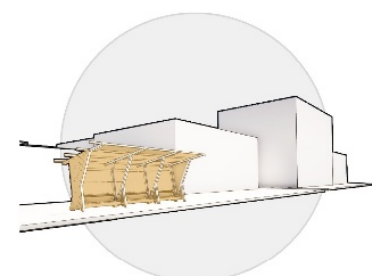

Bus stops
built with local materials

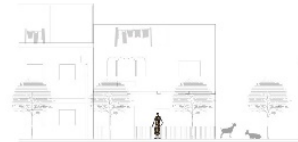

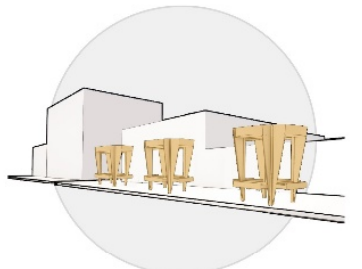

External sale stands ver most concurred roads (c

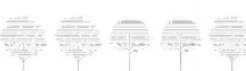

Endemic Strategies

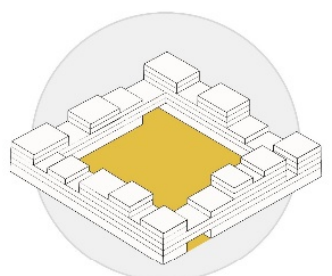

Densification

Floor area ratio $=2.22$
Coverage 0.47

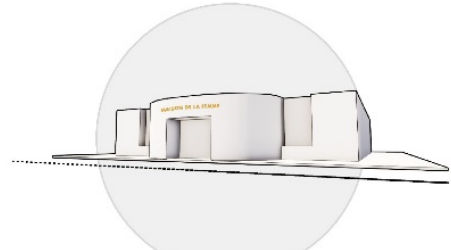

Maison de la Femme increase its capacity to host alphabetization

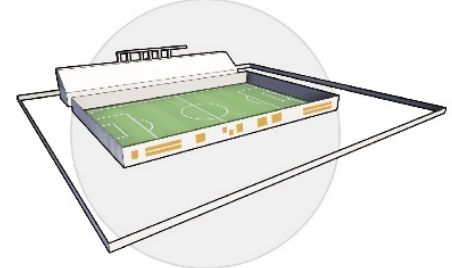

Historic wall - Stadium Sccond purpose as heritage hub:
storics and showerses of relcant figurse in
Senegal's history (create sense of belonging)

\section{Street Section}

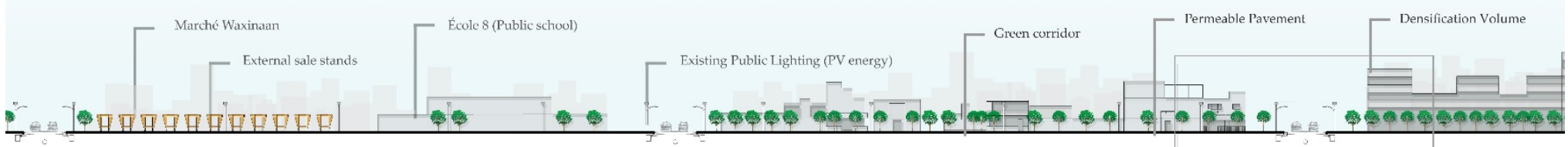

Figure 8. Fix and endemic strategies: street section for Scenario 2. 
The proper way to decide weight values for aspects or KPIs is through stakeholder discussion. For example, one weight assignation criterion could be to apply a larger weight to the population density KPI, as it is used to calculate the other two KPIs. In this case, however, a sensitivity analysis was implemented, using the walking weights tool, which shows dynamically the effects of altering the weights for each KPI. The weights were initially set at equal percentages and show the moment in which scenario 3 outranks another by assigning larger weights to KPIs in the incremental aspect.

Moreover, the results were examined through the web graph tool. These graphs allow comparing KPI assessment results in one same graph despite the difference in their measuring units. They also evidence a project scenario's strengths and weaknesses. Web graphs for each scenario are shown in Figure 9.

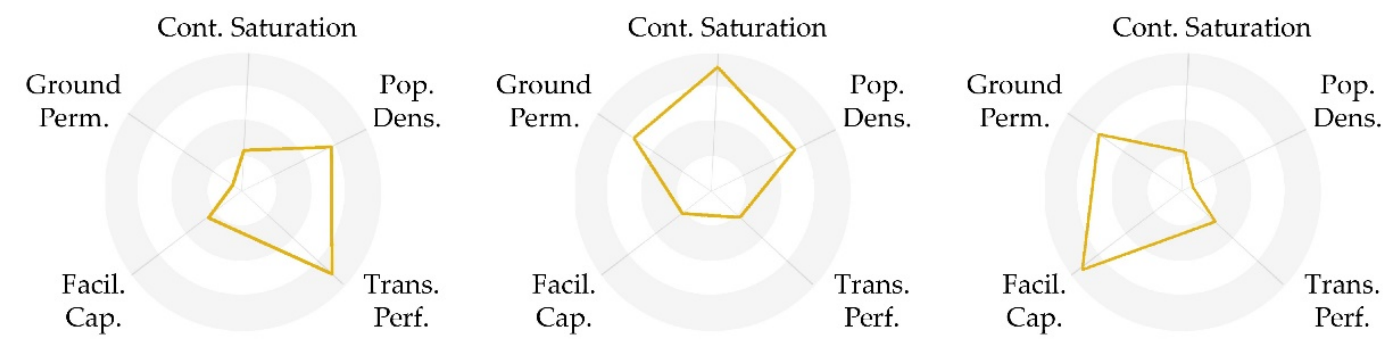

Figure 9. Web Charts for each Project Scenario (1, 2, 3 from left to right).

As seen from the charts, all three project scenarios are very distant from one another, at least under the selected criteria. This shows that the model created is effective when confronting different project alternatives that excel in different fields and placing them on the same level of comparison.

The scenarios formulated here are not to be taken as the final results of an incremental Pikine Est. As the definition exposed here says, these scenarios would be offering the initial steps to unleash incremental growth processes within the municipality, and they should be constantly monitored and assessed. Here lies the main premise for the requirements of future developments. A future inclusion and calculation of other KPIs will continuously enrich the results of this project, up to a point of determining which is the ultimate combination of strategies that compose the best scenario for incremental development.

\section{Conclusions and Future Developments}

Answering the general research question required an extensive process of study area analysis, literature review, and stakeholder discussions, as well as indicator identification, selection, assessment, and finally their application of decision aiding software.

It is important to recall that this study's initial remarks were the result of core problem identification, SWOT and stakeholder analysis, and the elaboration of the problem and objective trees. Although not included as graphic material in this study, the procedures for their elaboration were described to facilitate their application in other projects in contexts of developing communities. These led to an accurate indicator selection and KPI filtering, decisive elements within the course of project proposals.

This study proposed the integration of an incremental aspect as an LQI assessment category. The strategies devised for each project scenario, whether included in the incremental aspect or not may indeed be considered as incremental if they follow the principles of small scale, community involvement, and cost-restricted actions. Nonetheless, one must also examine the results of KPI assessment individually for each aspect. This is where we observed apparent discrepancies with the study's claims and the project scenario results: the incremental KPI is more performant within scenario 3, yet the MCA ranks it as the last one. However, this is an expected result according to the principles of weight assignation, as seen in Section 3. Future developments and projects should involve 
stakeholders as decision-makers who assign larger or smaller weights to each aspect or KPI to avoid these possibly confusing results of MCA.

Another suggestion promoted by this study is the efficacy of incremental interventions in urban areas composed by migrant population, especially in African contexts. Aware that there would naturally still be flows of people seeking better conditions elsewhere, a highly decisive factor for project performance evaluation would consist of calculating both the average duration of stay abroad and the number of people returning yearly to the country. Numerical data would help verify the success of the whole project in terms of combatting irregular migration.

It is relevant to mention that future projects must consider the issue of scarce data availability in African contexts. This element was decisive for indicator filtering processes and it will likely be observed as well in other projects replicating the methods in this study. Under these circumstances, data should be estimated using the information at hand or collected through in-site surveys and questionnaires. New data collected may help enrich future projects in the region and positively impact urban planning. For instance, having the possibility to communicate through actual data how often waste would be collected in the area or how far away citizens would be from the nearest public transport station is an actual privilege that could facilitate project implementation and acceptance. Future developments should also measure community participation levels in each project stage. Some future recommendations for project scenarios in African contexts are presented in Table 5.

Table 5. Future recommendations.

\begin{tabular}{lll}
\hline \multicolumn{1}{c|}{ Recommendation } & Description & Linkage to SDG's \\
\hline & & \\
& $\begin{array}{l}\text { Research and stakeholder comments } \\
\text { demonstrated that African population is largely } \\
\text { R1: Provide special attention to }\end{array}$ & $\begin{array}{l}\text { composed by people below thirty years of age. To } \\
\text { increase project reach, future scenarios should } \\
\text { the youth and women in each } \\
\text { project stage }\end{array}$ \\
& $\begin{array}{l}\text { involve youth. On the other hand, gender } \\
\text { equality is still a pressing issue in these contexts, } \\
\text { directly affecting LQI. }\end{array}$ \\
&
\end{tabular}

The social component is especially relevant in these contexts. Scenarios must be formulated from an interdisciplinary approach in order to kickstart incremental community development through bottom-up city building.

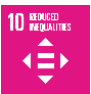

R2: Design interventions based on an integrated approach
R3: Promote better practices in citizenship through architecture and urbanism
Reconditioning traditional ways of living in order to gradually insert a sense of collective property and common space maintenance may raise awareness on the need to preserve public spaces and green areas, especially in peripheric communities. 
Table 5. Cont.

\begin{tabular}{|c|c|c|}
\hline Recommendation & Description & Linkage to SDG's \\
\hline $\begin{array}{l}\text { R4: Measure community } \\
\text { participation in each project stage }\end{array}$ & $\begin{array}{l}\text { This will consolidate an actual verification of the } \\
\text { impact of contributions from those who will } \\
\text { benefit directly from the project scenario. } \\
\text { Conclusions provided in this study remark upon } \\
\text { the fact that effectively implemented incremental } \\
\text { scenarios in African contexts must assess in } \\
\text { monitoring stages if the scenario's objectives } \\
\text { (contained in the objective tree) were actually } \\
\text { accomplished. }\end{array}$ & 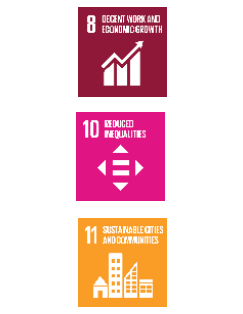 \\
\hline $\begin{array}{l}\text { R5: Create a network of local } \\
\text { institutions and project } \\
\text { stakeholders }\end{array}$ & $\begin{array}{l}\text { Involve local governmental and } \\
\text { community-formed institutions in the } \\
\text { development of the project scenarios. They will } \\
\text { directly point towards the critical areas to target } \\
\text { in each future scenario. In this study, local and } \\
\text { partnered institutions also proved useful in } \\
\text { selecting the right KPI thanks to the data and } \\
\text { insights they provided. Further feedback with } \\
\text { project stakeholders will also guide weight } \\
\text { assignation criteria for KPI assessment. }\end{array}$ & 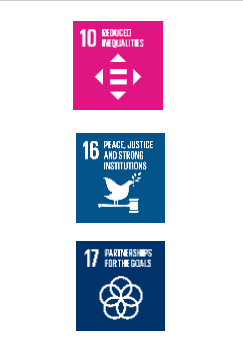 \\
\hline $\begin{array}{l}\text { R6: Implement principles of } \\
\text { incremental urbanism as a } \\
\text { response to scarce financial } \\
\text { resources in developing } \\
\text { communities }\end{array}$ & $\begin{array}{l}\text { Small scale interventions born from a community } \\
\text { conception are bound to be accurate and } \\
\text { adequate investments. However, multiple future } \\
\text { scenarios are conceivable. In order to adequately } \\
\text { be able to select the one most fitting and that best } \\
\text { follows incremental urban planning principles, } \\
\text { this study's results showed each scenario should } \\
\text { be assessed under LQI standards, introducing } \\
\text { among them an "incremental" aspect. Future } \\
\text { developments could also suggest assessing new } \\
\text { macro indicators within this aspect. }\end{array}$ & 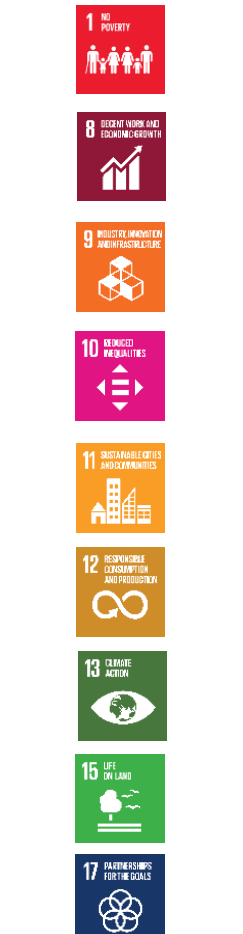 \\
\hline
\end{tabular}

The future of developing communities could be one of minimal infrastructural investments and strategies focused on the individual household and service facility improvement. If people are presented with the right opportunities for growth both at a plot and community scale, it could unleash a process of collective growth in which everyone is benefited without having to sacrifice traditional ways and customs of living. Incremental community planning could be given a new identity as a precise mechanism to propel developing communities into eco-positive environmental havens.

Author Contributions: Formal analysis, investigation, methodology, original draft preparation writing, graphic material elaboration, and scenario formulation: S.R.A.; formal analysis, investigation, methodology, original draft preparation reviewing, and supervision: S.T.M.; funding acquisition and supervision: P.L. All authors have read and agreed to the published version of the manuscript.

Funding: This research received no external funding. 
Acknowledgments: This article was elaborated upon the basis of "Creating and Assessing Scenarios for Incremental Community Development: A Case Study in Pikine Est", a master's degree thesis from the Polytechnic of Turin, by Santiago Restrepo Arias. Authors would also like to acknowledge the contributions of Paolo Mellano, Mario Artuso, and Gloria Tessarin, as well as the joint support provided by Alessandra Tosi, mayor of Pino Torinese, and Anna Valesano. Finally, the authors wish to acknowledge additional support from Pikine Est's mayor, Issakha Diop.

Conflicts of Interest: The authors declare no conflict of interest.

\section{Appendix A}

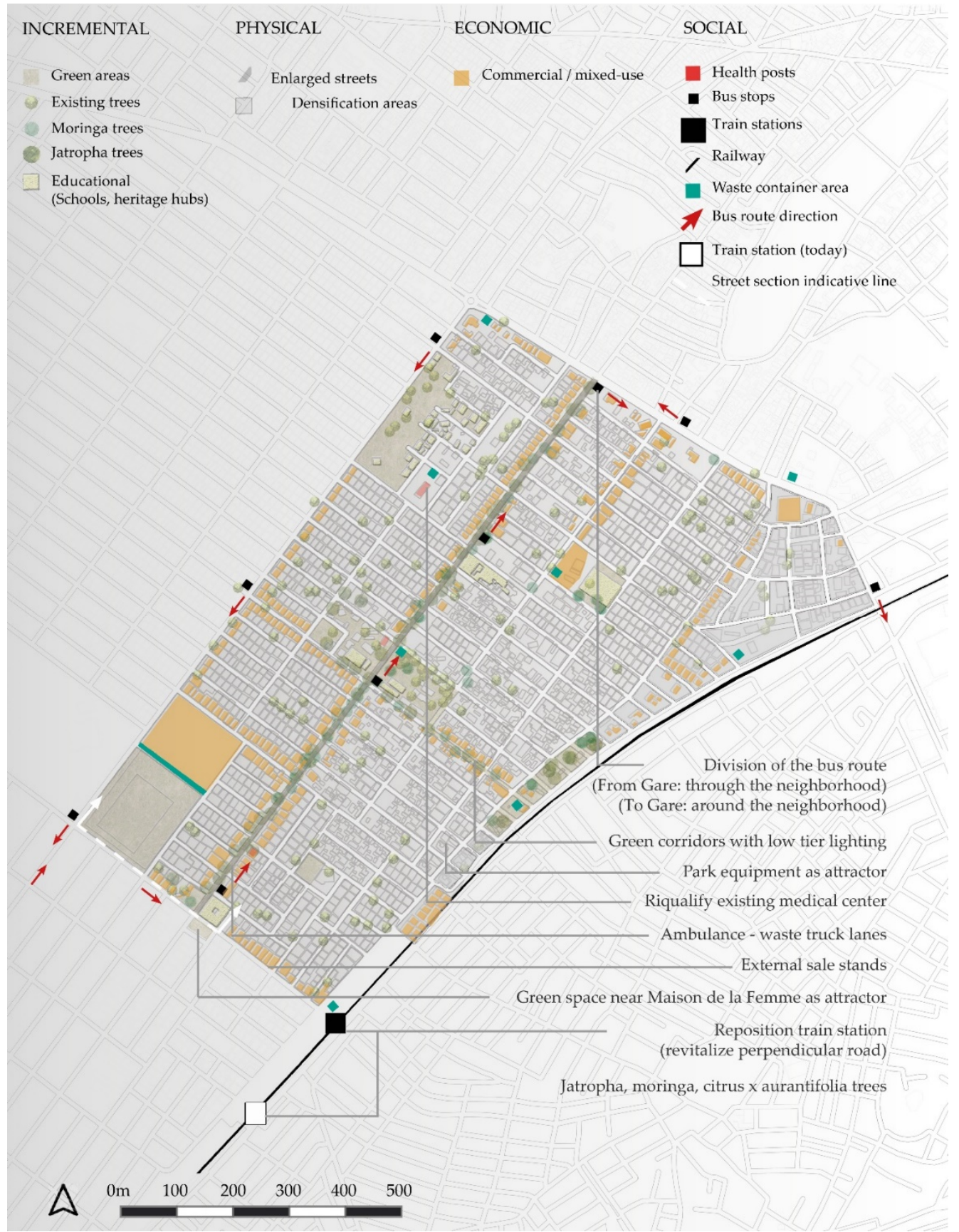

Figure A1. Intervention plan for Pikine Est according to Scenario 1. 
INCREMENTAL

Water Management

Literacy

Biodiversity

Heritage

\section{PHYSICAL}

Street Cleanness

Quality of the Roads

Housing Quality

Public Space Quality

ECONOMIC

Income

SOCIAL

Public Transport

Waste Management

Quality of the Facilities

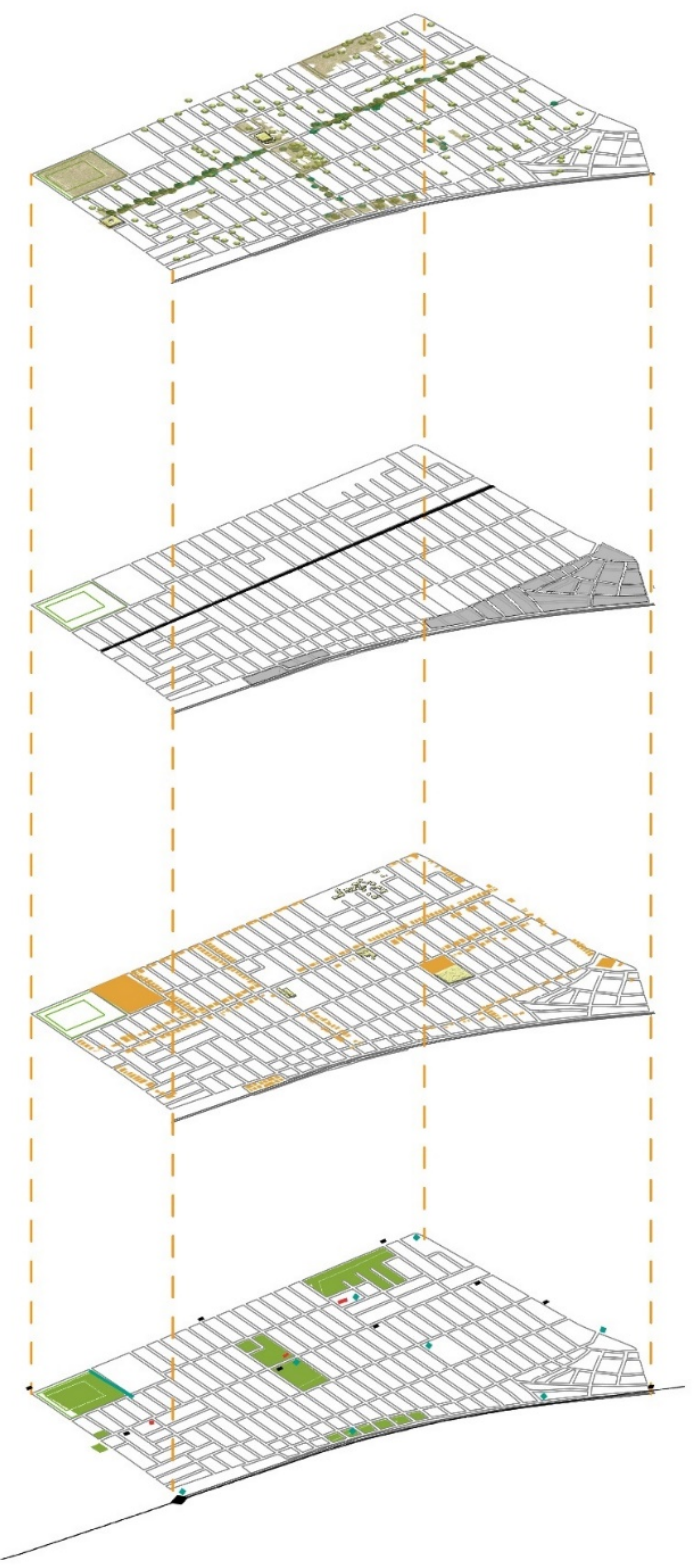

Figure A2. Exploded layers of site intervention for Scenario 1. 


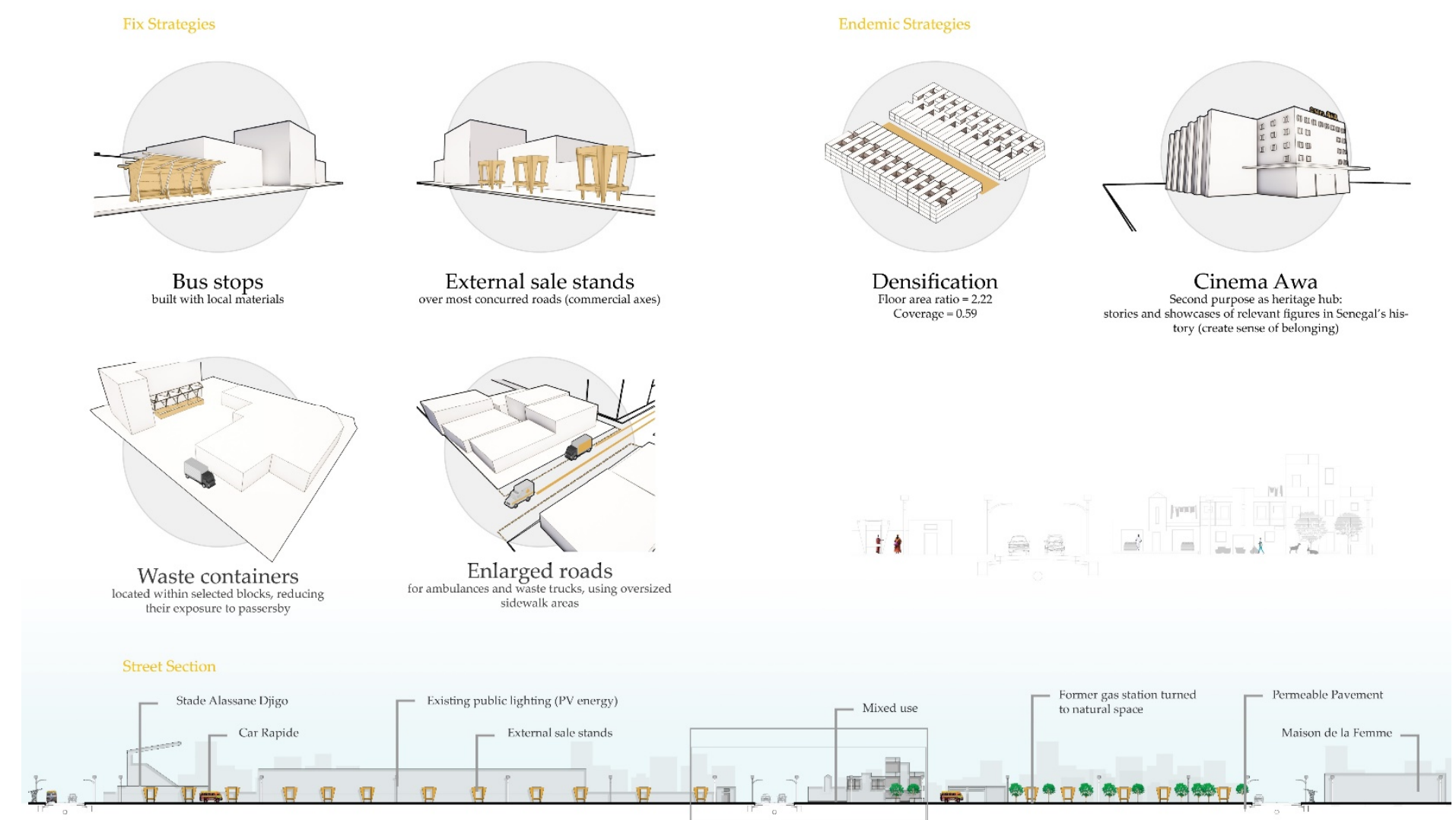

Figure A3. Fix and endemic strategies: Street section for Scenario 1. 


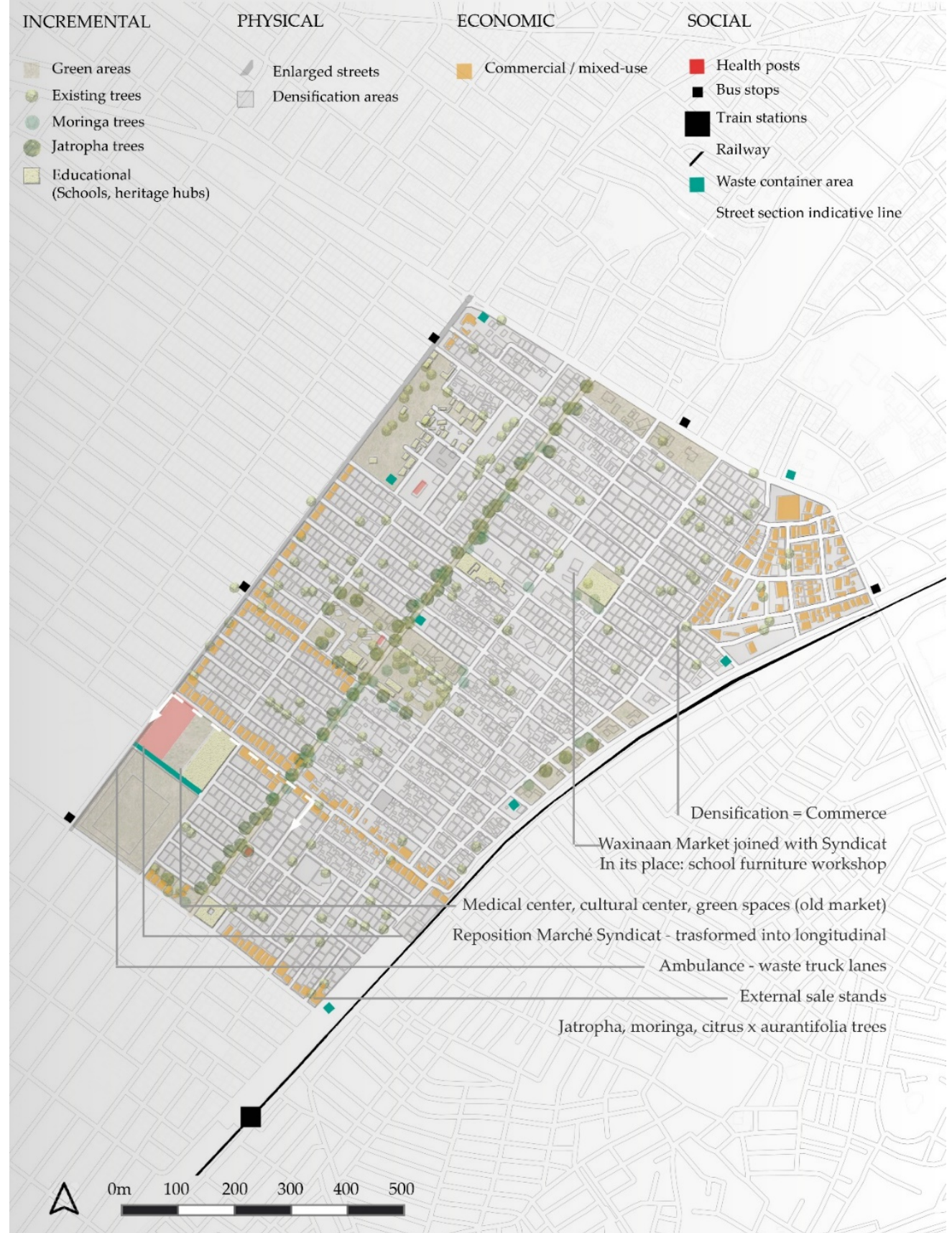

Figure A4. Intervention plan for Pikine Est according to Scenario 3. 


\section{INCREMENTAL}

Water Management

Literacy

Biodiversity

Heritage

\section{PHYSICAL}

Street Cleanness

Quality of the Roads

Housing Quality

Public Space Quality

\section{ECONOMIC}

Income

\section{SOCIAL}

Public Transport

Waste Management

Quality of the Facilities

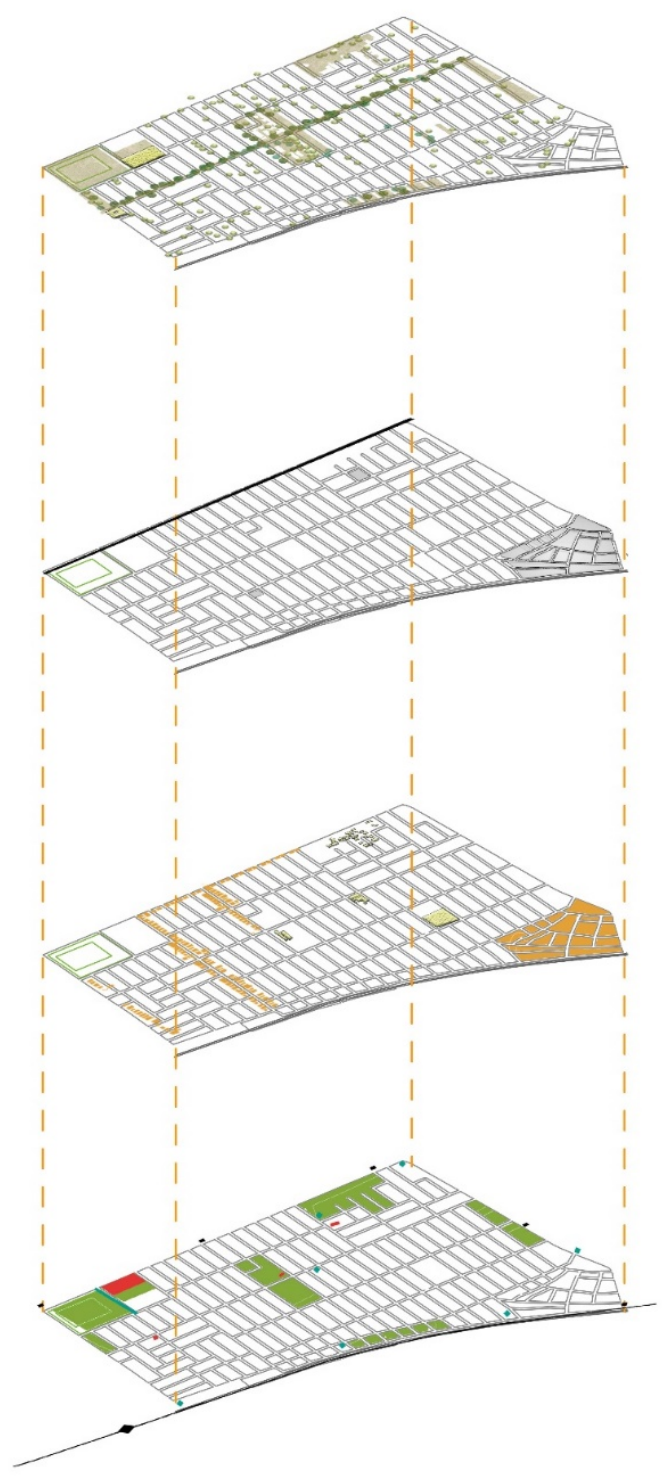

Figure A5. Intervention plan for Pikine Est according to Scenario 3. 
Fix Strategies

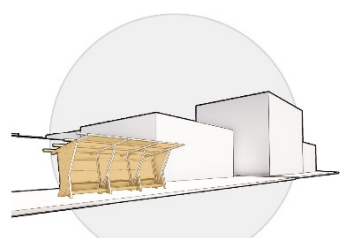
Bus stops
built with local materials

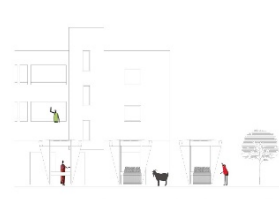

$\rightarrow$

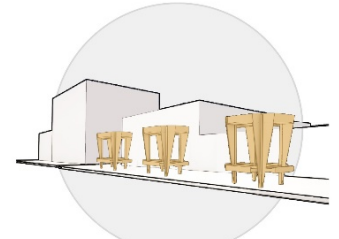

External sale stands
Endemic Strategies

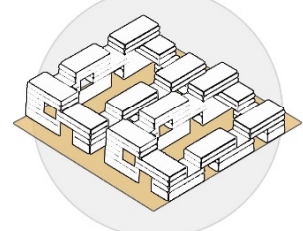

$\underset{\text { Floor area ratio }=1,90}{\text { Densification }}$ Floor area ratio $=1,90$
Coverage 0,35

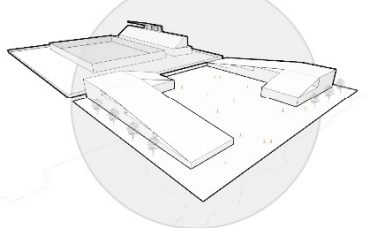

Old Market Square becomes a medical center, cultural center
and creates open natural spaces

Street Section

분

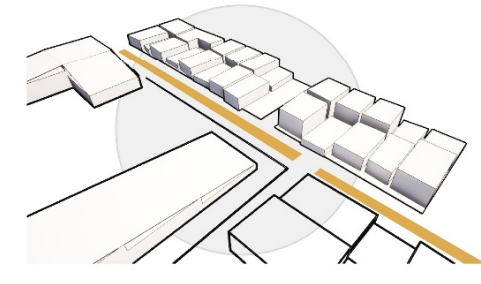

Longitudinal Markets

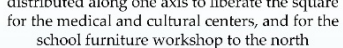

Longitudinal markets

Figure A6. Fix and endemic strategies: Street section for Scenario 3. 


\section{References}

1. Sow, F. Pikine, Senegal: A Reading of a Contemporary African City. Read. Contemp. Afr. City 1983, 7, 45-60.

2. United Nations (UN). 68\% of the World Population Projected to Live in Urban Areas by 2050, Says UN. Available online: https:/www.un.org/development/desa/en/news/population/2018-revision-of-worldurbanization-prospects.html (accessed on 22 March 2020).

3. Marans, R.W. Understanding environmental quality through quality of life studies: The 2001 DAS and its use of subjective and objective indicators. Landsc. Urban Plan. 2003, 65, 73-83. [CrossRef]

4. Dashora, L.K. Visualization of Urban Quality of Life at Neighbourhood Level in Enschede; International Institute for Geo-Information Science and Earth Observation: Enschede, The Netherlands, 2009.

5. Tesfazghi, E.S. Urban Quality of Life and Its Spatial Distribution in Addis Ababa: Kirkos Sub-City. Available online: https://webapps.itc.utwente.nl/librarywww/papers_2009/msc/upm/tesfazghi.pdf (accessed on 5 September 2020).

6. International Organization for Migration (IOM). Glossary on Migration; International Organization for Migration: Geneva, Switzerland, 2019.

7. Dovi, E.A. Migration: Taking rickety boats to Europe. In Africa Renewal; Special Edition on Youth, United Nations: New York, NY, USA, 2017.

8. Sané, Y. La décentralisation au Sénégal, ou comment réformer pour mieux maintenir le statu quo. Cybergeo Eur. J. Geogr. 2016. [CrossRef]

9. Thomet, N.; Vozza, A. Project Design Manual. A Step-by-Step Tool to Support the Development of Cooperatives and Other Forms of Self-Help Organization; International Labour Organization Publications: Geneva, Switzerland, 2010.

10. Cingolani, P.; Pastore, F.; Salis, E. Measuring Migration Costs of West African Migrants to Italy. Available online: https:/www.fieri.it/wp-content/uploads/2018/03/Migration-Costs-Italy-FIERI-14Mar2018-1.pdf (accessed on 7 July 2020).

11. Diawara, A.B. Les Déchets Solides a Dakar. Environnement, Sociétés et Gestion Urbaine; Université de Bordeaux III: Pessac, France, 2010.

12. Agence Nationale de Statistique et de la Démographie (ANSD). Migration au Sénégal. In Profil Migratoire 2018; ANSD: Dakar, Senegal, 2018.

13. Diop, K.; Tidiane Faye, C.A.; Sow, S.A. La Grande Niaye de Pikine, un espace humide à haute valeur agronomique au cœur de l'agglomération urbaine de Dakar: Analyse des enjeux socioéconomiques. Belg. J. Geogr. 2019. [CrossRef]

14. Baitsch, T. Incremental Urbanism A Study of Incremental Housing Production and the Challenge of its Inclusion in Contemporary Planning Processes in Mumbai, India; École Polytechnique Fédérale De Lausanne: Lausanne, Switzerland, 2018.

15. King, J. What Is the Incremental City? 2013. Available online: https://incrementalcity.wordpress.com/2013/ 02/09/what-is-the-incremental-city/ (accessed on 22 March 2020).

16. Steuteville, R.; Transect of Incremental Urbanism. Congr. New Urban. Available online: https://www.cnu.org/ publicsquare/2017/10/20/transect-incremental-urbanism (accessed on 4 September 2020).

17. Birkeland, J. Eco-Positive Design: Moving Beyond Ecological Restoration. Available online: https: //researchfeatures.com/wp-content/uploads/2018/08/Janis-Birkeland.pdf (accessed on 5 September 2020).

18. Dirutigliano, D.; Delmastro, C.; Torabi Moghadam, S. Energy efficient urban districts: A multi-criteria application for selecting retrofit actions Energy efficient urban districts: A multi-criteria application for selecting retrofit actions. Int. J. Heat Technol. 2017, 35, S49-S57. [CrossRef]

19. Torabi Moghadam, S.; Lombardi, P. Multi-Criteria Spatial Decision Support System for Urban Energy Planning: An Interdisciplinary Integrated Methodological Approach, In Sustainable Cities-Authenticity, Ambition and Dream; IntechOpen: London, UK, 2018; pp. 79-93.

20. Fals-Borda, O. Research for Social Justice: Some North-South Convergences. In Southern Sociological Society Meeting; Semantic Scholar: Atlanta, GA, USA, 1995.

21. Joslin, R.; Müller, R. The impact of project methodologies on project success in different contexts. Int. J. Proj. Manag. 2015, 33, 1377-1392. [CrossRef]

22. Comune di Pino Torinese, Bando Piemonte \& Africa sub-Sahariana-Partenariati Territoriali per un Futuro Sostenibile; Municipality of Pino Torinese: Pino Torinese, Italy, 2018. 
23. United Nations Educational Scientific and Cultural Organization. UNESCO Global Partnership for Girls' and Women's Education-One Year on. 2012. Available online: https://pax.unesco.org/cp/factsheets_ed/SN_ EDFactSheet.pdf (accessed on 7 July 2020).

24. Morton, K.L.; Atkin, A.J.; Corder, K.; Suhrcke, M.; Turner, D.; Van Sluijs, E.M.F. Engaging stakeholders and target groups in prioritising a public health intervention: The Creating Active School Environments (CASE) online Delphi study. BMJ Open 2017, 7, 1-12. [CrossRef] [PubMed]

25. Moro, A.; iiSBE Italia R\&D. Testing Protocol Key Performance Indicators Urban Scale; CESBA MED: Sustainable Cities, Italy, 2018.

26. Sang, Å.O.; Tveit, M.S. Capturing Landscape Visual Character Using Indicators: Touching Base with Landscape Aesthetic Theory. J. Landsc. Res. 2008, 33, 89-117. [CrossRef]

27. Cruz, P.M.D.; Mateu, J. Mapping the Quality of Life Experience in Alfama: A case study in Lisbon, Portugal. Haptics Sci. Technol. Appl. 2011, 6782, 269-283.

28. Stephen, O.E.; Assessment of Quality of Life Using GIS. Geospatial World. 2013. Available online: https: //www.geospatialworld.net/article/assessment-of-quality-of-life-using-gis/ (accessed on 4 September 2020).

29. United Nations (UN). Glossary of Environment Statistics; United Nations: New York, NY, USA, 1997.

30. Wang, H.G. Preparing to Manage Natural Hazards and Climate Change Risks in Dakar, Senegal. Available online: https:/reliefweb.int/sites/reliefweb.int/files/resources/GFDRR_Climate_and_Natural_Hazard_Risks_ Dakar_Senegal.pdf (accessed on 4 September 2020).

31. Prothmann, S. Urban Identities and Belonging: Young Men's Discourses about Pikine (Senegal). Int. Dev. Policy Rev. Int. Polit. Dev. 2018, 254-274. [CrossRef]

32. Salem, G. La Santé Dans La Ville. Géographie d'un Petite Espace Dense: Pikine (Sénégal); Karthala: Paris, France, 1998.

33. Brinkhoff, T. Pikine Est-Commune in Senegal. 2013. Available online: https://www.citypopulation.de/en/ senegal/dakarcity/admin/pikine_dagoudane/SN01031212_pikine_est/ (accessed on 4 September 2020).

34. Open Street Map Foundation (OSMF). OpenStreetMap. 2019. Available online: www.openstreetmap.org (accessed on 4 September 2020).

35. Agence Nationale de Statistique et de la Démographie (ANSD). Recensement Général de la Population et de l'Habitat, de l'Agriculture et de l'Elevage; Rapport Definitif, ANSD: Dakar, Senegal, 2014. Available online: https://www.ipar.sn/IMG/pdf/rapport-definitif-rgphae_2013_0.pdf (accessed on 4 September 2020).

36. Association for Public Service Excellence (APSE). Street Cleansing Performance Indicators. 2018. Available online: http://www.apse.org.uk/apse/assets/File/Street\%20Cleansing.pdf (accessed on 4 September 2020).

37. Horak, E.; Emery, S.; Agaienz, A. Key Performance Indicators for Road Infrastructure Asset Management by a Roads Agency in a large Local Authority. In Proceedings of the Meeting the Transport Challenges in Southern Africa, Pretoria, South Africa, 16-20 July 2001. Available online: https://repository.up.ac.za/ bitstream/handle/2263/7970/2a7.pdf?sequence=1 (accessed on 4 September 2020).

38. Dickinson, M.; Platten, A.; Dobrashain, T.; Furlonger, J. Development of Key Performance Indicators For Housing Market Renewal New Build. Available online: https://www.irbnet.de/daten/iconda/CIB1860.pdf (accessed on 4 September 2020).

39. Vial, D.; Prior, M. Use of Key Performance Indicators in the Planning and Management of Public Open Space. Parks \& Leisure Australia National Conference. 2003. Available online: https://www.researchgate.net/publication/295010492_Use_of_Key_Performance_Indicators_in_the_ Planning_and_Management_of_Public_Open_Space (accessed on 4 September 2020).

40. Spider Strategies-KPI Dashboards. Example KPIs for the Waste Management and Remediation Services Industry. Available online: https://kpidashboards.com/kpi/industry/administrative-and-support-wastemanagement-and-remediation-services/ (accessed on 4 September 2020).

41. Eboli, L.; Mazzulla, G. Performance indicators for an objective measure of public transport service quality. Eur. Transp. Trasp. Eur. 2012, 51,1-21.

42. Majale, M. Employment creation through participatory urban planning and slum upgrading: The case of Kitale, Kenya. Habitat Int. 2008, 32, 270-282. [CrossRef]

43. Jackson, T. Key Performance Indicators For Schools \& Education Management. Clear Point Strategy. Available online: https://www.clearpointstrategy.com/key-performance-indicators-in-education/ (accessed on 4 September 2020). 
44. Mahy, G.; Pitz, C. Performance Indicators Framework for Biodiversity Management in Gypsum Quarries Throughout Europe. 2015. Available online: http://www.eurogypsum.org/wp-content/uploads/2015/04/ EUROGYPSUMPERFORMANCEINDICATORSBD.pdf (accessed on 21 October 2019).

45. Ferrada, M.; Landscape of the Urban Shoreline of Valparaíso: Towards the Establishment of Indicators for the Dynamic Preservation of Change. Meas. Herit. Conserv. Perform. Available online: https:/www.iccrom.org/ sites/default/files/ICCROM_19_Measuring-Heritage-Performance03_en.pdf (accessed on 4 September 2020).

46. The Alliance Africa. Africa Co-Operative Development Strategy 2017-2020. 2016. Available online: https://icaafrica.coop/sites/default/files/basic-page-attachments/africa-cooperative-development-strategy2017-2020-859927886.pdf (accessed on 4 September 2020).

47. Poulsen, E. Integrating Gender and Nutrition with Agricultural Extension Services Senegal Landscape Analysis. 2015. Available online: http://ingenaes.illinois.edu/wp-content/uploads/ING-Landscape-Study-2016-Senegalpublished-2015_12_20.pdf (accessed on 23 June 2020).

48. Jordy, D.J.-J.; Diou, C. Flood Prevention and Drainage Project; International Bank for Reconstruction and Development (IBRD): Dakar, Senegal, 2011.

49. a $+\mathrm{t}$ research group. 50 Urban Blocks; $\mathrm{a}+\mathrm{t}$ architecture publishers: Vitoria-Gasteiz, Spain, 2017.

50. Prestige and L'Atelier Urbain, Projet de Gestion des Eaux Pluviales et D'adaptation au Changement Climatique; L'Atelier Urbain: Dakar, Senegal, 2014. Available online: http://www.pdudakar.gouv.sn/IMG/pdf/note_de_ pre_sentation_de_la_cartographie_pud_pikine_et_gue_diawaye.pdf (accessed on 26 August 2020).

51. Reforestaction. Reforestation in Senegal. 2011. Available online: https://www.reforestaction.com/en/ reforestation-senegal (accessed on 4 September 2019).

52. Engineering Toolbox. Room Area per Person. 2003. Available online: https://www.engineeringtoolbox.com/ number-persons-buildings-d_118.html (accessed on 15 October 2019).

(C) 2020 by the authors. Licensee MDPI, Basel, Switzerland. This article is an open access article distributed under the terms and conditions of the Creative Commons Attribution (CC BY) license (http://creativecommons.org/licenses/by/4.0/). 